\title{
Strategies to Enhance the Performance of Electrochemical Capacitors Based on Carbon Materials
}

\author{
David Salinas-Torres ${ }^{1,2 *}$, Ramiro Ruiz-Rosas ${ }^{3}$, Emilia Morallón ${ }^{2}$ and \\ Diego Cazorla-Amorós ${ }^{4}$
}

\begin{abstract}
1 Division of Materials and Manufacturing Science, Graduate School of Engineering, Osaka University, Osaka, Japan, ${ }^{2}$ Departamento de Química Física, Instituto Universitario de Materiales, University of Alicante, Alicante, Spain,

${ }^{3}$ Departamento de Ingeniería Química, University of Málaga, Málaga, Spain, ${ }^{4}$ Departamento de Química Inorgánica, Instituto Universitario de Materiales, University of Alicante, Alicante, Spain
\end{abstract}

OPEN ACCESS

Edited by:

Ashok K. Sundramoorthy,

SRM Institute of Science and

Technology, India

Reviewed by:

Thiagarajan Soundappan,

Navajo Technical University,

United States

Rajib Paul,

Case Western Reserve University,

United States

Sorin Melinte,

Catholic University of Louvain

Belgium

*Correspondence:

David Salinas-Torres

david@mat.eng.osaka-u.ac.jp david.salinas@ua.es

Specialty section:

This article was submitted to

Carbon-Based Materials,

a section of the journal

Frontiers in Materials

Received: 14 January 2019

Accepted: 07 May 2019

Published: 29 May 2019

Citation:

Salinas-Torres $D$, Ruiz-Rosas $R$ Morallón E and Cazorla-Amorós D (2019) Strategies to Enhance the Performance of Electrochemical

Capacitors Based on Carbon

Materials. Front. Mater. 6:115

doi: 10.3389/fmats.2019.00115
The increasing worldwide energy consumption has contributed to both the vast growth of greenhouse emissions from carbon-containing fuels-based sources (coal, petroleum, etc.) and the depletion of the aforementioned sources. Given this scenario, the development of inexpensive and high-performing energy storage devices, which have the least possible environmental impact, is needed. At this point, electrochemical capacitors (ECs) or supercapacitors are a particular alternative or complementary option to batteries and fuel cells (FCs). ECs present high power output and long cycle life, but little power density compared to conventional or Lithium-ion batteries. Therefore, ECs are going to play a pivotal role, not only in portable electronic devices, but also to provide power density in hybrid electric vehicles. Many efforts have been focused on improving the energy output of ECs, although its enhancement keeping the high power density is still the cornerstone of most investigations. Many studies have been conducted toward the development of electrode materials such as metal oxides, conducting polymers or novel carbons. Nevertheless, they have shown important shortcomings to be implemented (i.e., high cost, low electrical conductivity, poor stability, etc.). Recent studies put the spotlight on nitrogen-containing carbon materials as candidates to improve the ECs performance in terms of energy. Optimizing the ECs configuration (asymmetric and hybrid) is another approach reported to tackle the challenge. Additionally, it is important to mention that the design of carbon materials obtained from inexpensive precursors lately attracted the attention of the research community. This review compiles works performed in our research group over the last years. The effect of nitrogen groups present in the carbon network on the capacitance will be reported and the study of asymmetric configuration to enhance de energy density will be discussed, either opening the potential window or by increasing the capacitance. Moreover, a lignin-based ECs will be described as an environmentally friendly approach. Finally, perspective and conceivable research guidelines in order to hurdle the challenges proposed to implement the carbon materials in the field of ECs will be addressed.

Keywords: supercapacitors, N-doped carbon materials, lignin, green chemistry, asymmetric, flexible 


\section{INTRODUCTION}

The use of energy has helped the development of human civilization and different ways to obtain and to exploit energy have been considered along the history. Nowadays, the authorities have boosted the utilization and development of renewable energies, which have been accompanied by the outstanding advances in energy storage devices to face the decoupling between the energy generation from these renewable technologies and the energy demand. ECs are considered promising devices to store and supply energy efficiently. Unlike conventional capacitors that store energy (a few $\mathrm{mF}$ of capacitance) through an electric field, ECs consist of two electrodes generally based on nanostructured porous carbon materials within an electrolyte, in which electrical energy storage on the electrode can occur through two mechanisms. The first one is the formation of the electric double layer (EDL) by adsorption, desorption or ion-exchange of ions at the electrolyte/electrode interface (capacitive process), and the second consists on faradic reactions at the surface of the electrodes (pseudocapacitive process) (Conway, 1999; Simon and Gogotsi, 2008; Brousse et al., 2015). Hence, ECs are classified as electric double-layer capacitors (EDLC) or pseudocapacitors. However, according to the composition of the electrode materials, these are also classified as symmetric, asymmetric or hybrid systems. Even though EC can store much more energy per unit volume/mass than conventional capacitors, it is still not enough so that ECs have to be used in specific applications or combined with other generation and storage systems. Therefore, an important part of the research in the field of ECs is dedicated to enhance the energy density without changing their usual high power output $\left(>10 \mathrm{~kW} \mathrm{~kg}^{-1}\right)$ and to increase their lifetime.

The maximum energy stored in an EC is given by Equation (1) (that can be applied to EDL capacitors):

$$
E_{\max }=\frac{1}{2} C V_{\max }^{2}
$$

The improvement in both capacitance (C) and maximum operating cell voltage $\left(\mathrm{V}_{\max }\right)$ results in ECs with high energy density, leading to reliable devices able to deliver high power and to harvest energy quickly. The easiest way to increase the capacitance is to increase specific surface area (SSA) of the electrode.

The maximum power delivered in an EC is expressed as:

$$
P_{\max }=\frac{V_{\max }^{2}}{4 E S R}
$$

$\mathrm{P}_{\max }$ depends on the square of cell voltage and the equivalent series resistance (ESR) that encompasses resistive contributions of the ECs components. From Equations (1) and (2), it is clear that voltage has a stronger effect on the performance than capacitance. The capacitance is related to the design of the electrode material, while an increase in the cell voltage is associated with the electrolyte or the device configuration. However, the previous assertion is in fact inaccurate, for instance, it was demonstrated that the tailoring of the surface chemistry of porous carbon materials used as electrodes to increase the capacitance, also extended the maximum operating cell voltage (Bleda-Martínez et al., 2008b; Salinas-Torres et al., 2013; Mostazo-López et al., 2015) and it was also observed that the design of electrolyte to expand the operating voltage resulted in an improvement in terms of specific capacitance (Leyva-García et al., 2016b; Schütter et al., 2016). This correlation between the carbon surface and electrolyte in the formation of EDL was shown in the literature (Deschamps et al., 2013; Forse et al., 2016; Oschatz et al., 2016). Therefore, regardless of the strategy chosen to enhance the ECs performance, the improvement in both capacitance and voltage can occur. Accordingly, it is crucial to study the connection among different parameters (chemical composition, pore structure, interaction electrolytesurface, etc.) to maximize the EC performance. Since the most used materials in manufacturing electrodes are the nanoporous and nanostructured carbon materials (NCMs), the next sections will be focused on the state-of-the-art of carbon based ECs components (electrode materials and electrolytes) as well as on recent investigation conducted in our research group.

\section{STATE-OF-THE-ART OF EC COMPONENTS}

This section includes information about the development of carbon materials and their composites used as electrodes to enhance properties such as capacitance, electrical conductivity as well as new electrolytes with higher operating potential windows, which improve the capacitor performance. Finally, a brief explanation of ECs configurations will be included.

\section{Electrode Materials}

It is well-known that NCMs are the most used materials as electrode in ECs, which is due to the combination of high surface area, good electrical conductivity, diversity of structures and a large variety of porous textures. NCMs also present other characteristics, which are not less important, such as high chemical and thermal stability, control of morphology and surface chemistry and wide operating potential range. In addition, from the industrial viewpoint, their non-toxicity, abundance and easy processability make them excellent materials for electrode manufacturing. This section encompasses a summary of the main types of NCMs used as electrode material in ECs, as well as the combination with other electroactive materials.

\section{Outline of the Main Types of NCMs}

Activated carbons (ACs) are the conventional carbon materials used as electrodes in commercial ECs because they have specific surface areas larger than $1,000 \mathrm{~m}^{2} \mathrm{~g}^{-1}$, high pore volume, suitable electrical properties and moderate cost (Sevilla and Mokaya, 2014), delivering high capacitance values in both aqueous and organic electrolyte ( $>200 \mathrm{~F} \mathrm{~g}^{-1}$ and $\sim 120 \mathrm{~F} \mathrm{~g}^{-1}$, respectively). A way to improve the capacitance would be to increase the SSA. However, the capacitance deviates from the linearity with the SSA at very high SSA (Bleda-Martínez et al., 2010), what can be explained attending to their pore structure. ACs are usually synthesized by chemical or physical activation of carbon precursors (Lozano-Castelló et al., 2001; Bleda-Martínez et al., 
2010; Falco et al., 2013), leading to NCMs that possess an important contribution of narrow micropores $(<0.5 \mathrm{~nm})$ and random pore pathways, which hamper the electrolyte ions transport, mainly in organic electrolytes (Fuertes et al., 2004; Liu et al., 2011). For this reason, many works have been addressed to constrain the PSD in the range of mesopores (2$50 \mathrm{~nm}$ ) and improve the accessibility to the porosity. These are named as ordered mesoporous carbons (OMCs), which are prepared using a hard or soft template ( $\mathrm{ZnO}, \mathrm{SBA}-15$, copolymer F127, etc.) (Zhou et al., 2003; Li et al., 2007, 2011; Liu et al., 2011; Jiang et al., 2014; Du et al., 2018; Yoshida et al., 2018), and have achieved remarkable electrochemical performance at high current densities, but their relatively low SSA limits the capacitance value. Alternatively, Itoi et al. (2011) used the zeolite $\mathrm{Y}$ as template, obtaining a zeolite-templated carbon (ZTC) with interconnected pores and a high SSA $(\sim 3,000$ $\left.\mathrm{m}^{2} \mathrm{~g}^{-1}\right)$. In addition, the PSD displayed essentially pores of size of $1.2 \mathrm{~nm}$ and exhibited both good gravimetric and volumetric capacitance, attributed to the pore structure matching the radius of naked electrolyte ions, which was in agreement with previous works (Chmiola et al., 2008; Largeot and Portet, 2008). This effect was also observed in the carbide derived-carbons (CDCs) that have pores smaller than $1 \mathrm{~nm}$, leading to an anomalous rise in capacitance (Chmiola et al., 2006). Bearing in mind that micropores enhance the capacitance and meso-macropores facilitate the ion diffusion at high currents, the NCMs with micro-mesopores well-interconnected by macropores would be a promising alternative for ECs (Qie et al., 2013; ValeroRomero et al., 2014). Hierarchical porous carbons (HPCs) fulfill these features and they could achieve ECs with outstanding performance (Wang et al., 2008; Xia et al., 2008; Qie et al., 2013; Li et al., 2014; Ruiz-Rosas et al., 2014; Salinas-Torres et al., 2016). Wang et al. (2008) reported a hierarchical porous graphitic carbon (HPGC) with micropores, mesopores walls, and macropores, which provided a capacitance value larger than 220 $\mathrm{Fg}^{-1}$ in $6 \mathrm{M} \mathrm{KOH}$ (relatively high in alkaline solution). Moreover, it delivered a two-fold energy and power density values (5.7 Wh $\mathrm{Kg}^{-1}$ and $10 \mathrm{~kW} \mathrm{~kg}^{-1}$ ) compared to a commercial AC measured at the same conditions and using a two-electrode cell.

There is also an important piece of research on the use of carbon nanotubes (CNTs) which possess a high electrical conductivity, what is very important to reduce ESR in the device. However, their relatively low SSA has hindered their further development in this application because capacitance values are limited in a two electrode cell $\left(<50 \mathrm{~F} \mathrm{~g}^{-1}\right)$ (Frackowiak et al., 2000, 2002; Lee et al., 2001; Yoon et al., 2004). Therefore, several strategies have focused on increasing the SSA by chemical or electrochemical treatments (Frackowiak et al., 2002; Ye et al., 2005a) or by synthesizing arrays or sponge-like foams which displayed an open porous structure compared to those obtained from CNT films (Futaba et al., 2006; Hsia et al., 2014). Recently, graphene (2D NCM) has also been studied as electrode material in ECs. This material has a theoretical high SSA, high electrical conductivity and the possibility to produce different architectures (Lee J. S. et al., 2013; Yoon et al., 2014; Miller and Outlaw, 2015; Yang et al., 2019). Thus, graphene is a good candidate to prepare binderless electrodes, in which the use of electrical conductivity promotor and even the collector could be avoided. However, the main drawback to make graphene-based ECs is the stacking of graphene sheets that causes an important loss of accessible SSA. Graphene-related materials, mainly reduced graphene oxide (rGO), have also been studied (Yoo et al., 2011; Zhu et al., 2011). Yoo et al. (2011) reported a rGO-based EC with a remarkable energy density $9.7 \mathrm{Wh} \mathrm{kg}^{-1}$, although this value was obtained for electrodes with a very low thickness and its comparison to other NCMs would not be accurate.

Despite the aforementioned progress, many challenges still have to be overcome in the design of carbon-based electrode materials to enhance the capacitance. For this reason, other approaches have also been explored to improve the specific capacitance and electrical conductivity. One of them, taking into account the carbon materials mentioned above, deeps into new structural designs such as mesoporous carbon spheres or carbon nanofiber arrays (Nakamura et al., 2006; Liu et al., 2009, 2010; Wang et al., 2009; Huang et al., 2017), well-aligned free-standing mesoporous carbon nanofibers or CNTs (Esconjauregui et al., 2010; Li et al., 2011; Kang et al., 2013; Yan et al., 2013; Arcila-Velez et al., 2014), interconnected porous carbon fibers (Berenguer et al., 2016), and so on.

\section{Doped NCMs: An Approach to Enhance the Capacitor Performance}

The surface functionalization is another strategy to enhance the capacitor performance. NCMs have been modified by introducing various heteroatoms $(\mathrm{O}, \mathrm{N}, \mathrm{S}, \mathrm{B}, \mathrm{P}, \mathrm{Si}$, etc.) into the carbon network (Hulicova-Jurcakova et al., 2009a; Deng et al., 2015; Liu Z. et al., 2015; Mostazo-López et al., 2015; Xiang et al., 2017; Inagaki et al., 2018). However, nitrogen and oxygen are the most common heteroatoms used to synthesize heteroatom-doped NCMs for their use as electrodes in ECs. Obviously, oxygen has been widely studied because of its inherent presence in the carbon materials. Oxygen functionalities are easily introduced in NCMs by chemical reactions with activating or oxidizing agents. A wide variety of oxygencontaining functionalities can be found in NCMs, such as phenol, carbonyl, ether, carboxylic and quinone groups among others (Figueiredo et al., 1999). Although, it has been established that only quinone groups (CO-type) are electrochemically active in acidic electrolytes (Hsieh and Teng, 2002; Bleda-Martínez et al., 2005; Seredych et al., 2008), the oxygen groups play a key role in the capacitance performance, since they modify the wettability of the surface, the reactivity and the electrical conductivity of the material. Oxygen-functional groups also revealed electrochemical activity in basic electrolyte (Liu et al., 2008; Xu et al., 2015). Xu et al. (2015) reported that a graphitized CDC treated in $\mathrm{HNO}_{3}$ improved its wettability, which in turn increased its capacitance from 11 to $146 \mathrm{~F} \mathrm{~g}^{-1}$, showing the important contribution of oxygen-functional groups in the capacitance of the carbon materials. Zhao Y. et al. (2015) reported that a suitable combination of a high amount of oxygen groups (13 wt.\%) with porous texture for HPC improved the capacitance in both acid and basic medium. Oxygen groups also show pseudocapacitance in organic electrolyte. In this sense, Nueangnoraj et al. (2015) reported the electrochemical behavior 
of ZTC with a high amount of oxygen-functional groups (14.4 wt.\%) in organic electrolyte. This large capacitance was related to the redox-active functional groups based on the formation of quinone anion radicals and ether cation radicals.

Concerning the nitrogen-functional groups, they have attracted increasing attention from researchers as good candidates to modify the carbon network because their incorporation can lead to the improvement in electrochemical behavior compared to the pristine NCM mainly because of their contribution to double layer capacitance or pseudocapacitance (Kwon et al., 2009; Yang et al., 2010; Lei et al., 2011; Ornelas et al., 2014; Wei et al., 2016), wettability improvement (Kwon et al., 2009; Yang et al., 2010; Candelaria et al., 2012), stabilizing effect (i.e., decrease of material reactivity) (Salinas-Torres et al., 2015) and electron donor capability (Seredych et al., 2008; Wang et al., 2013). There are many methods to introduce nitrogen-functional groups in NCMs such as reaction with $\mathrm{N}$-containing source $\left(\mathrm{NH}_{3}\right.$, urea, $\mathrm{NO}$, etc.), carbonization of a N-containing precursor (melamine, pyridine, etc) and thermal treatment of $\mathrm{N}$-containing precursors infiltrated into a template (Raymundo-Piñero et al., 2002; Xia and Mokaya, 2004; Kruk et al., 2005; Bleda-Martínez et al., 2008a; Inagaki et al., 2010; Nishihara and Kyotani, 2012; Shen and Fan, 2013; Mostazo-López et al., 2015, 2016; Salinas-Torres et al., 2015; Quílez-Bermejo et al., 2017). Using these methods, the most common nitrogen-functional groups generated are pyridine, quaternary $\mathrm{N}$, pyrrole and oxidized $\mathrm{N}$ species. It is extensively accepted that pseudocapacitance is related to pyridine or pyrrole groups located at the edges of the graphene layers (Lota et al., 2005; Lei et al., 2011; Su et al., 2011; Ornelas et al., 2014; Wei et al., 2016). While quaternary $\mathrm{N}$ and oxidized $\mathrm{N}$ species do not produce faradic reactions, their positive charge density can enhance the capacitance and promote the electron transfer (Seredych et al., 2008; Hulicova-Jurcakova et al., 2009b; Wei et al., 2016). Sun et al. (2014) reported a nitrogen-doped porous graphitic carbon (NPGC) with both high SSA of $1,027 \mathrm{~m}^{2}$ $\mathrm{g}^{-1}$ and nitrogen content (7.7 wt\%). NPGC presented a high capacitance value in $6 \mathrm{M} \mathrm{KOH}\left(293 \mathrm{~F} \mathrm{~g}^{-1}\right)$ and then, ECs based on NPGC exhibited high energy density value $\left(8.1 \mathrm{Wh} \mathrm{kg}^{-1}\right)$ at a high power density. This outstanding performance was particularly attributed to the nitrogen-functional groups, which improved the wettability, the electrical conductivity and the electron transfer rate. The effect of the nitrogen-functional groups on ECs performance was also reported by Zhao J. et al. (2015). Hierarchical nitrogen-doped carbon nanocages (hNCNCs) were compared to their equivalent sample without nitrogen (hCNCs). The hNCNCs displayed a very high specific capacitance up to $313 \mathrm{~F} \mathrm{~g}^{-1}$ in $6 \mathrm{M} \mathrm{KOH}$ and ECs constructed with hNCNCs reached a maximum energy density value of $10.9 \mathrm{~W} \mathrm{~h} \mathrm{~kg}^{-1}$ while those based on hCNCs exhibited only $7.9 \mathrm{~W}$ $\mathrm{h} \mathrm{kg}^{-1}$. To a certain extent, the better hNCNCs performance was associated to $\mathrm{N}$-doping that improved the hydrophilicity, which in turns increased both ion-accessible surface and the capacitance. To summarize, nitrogen- functional groups not only enhance the capacitance by faradic reactions but also improve the hydrophilicity and electron transfer rate, which in turn cause the improvement in capacitance performance in ECs.
Regarding other heteroatoms, their effect on the capacitance still remains unclear. However, co-doping processes of some heteroatoms with nitrogen or oxygen-functional groups have shown a synergistic effect (Hulicova-Jurcakova et al., 2009a,c; Wen et al., 2016). Yan et al. (2014) indicated that, despite their low SSA $\left(\mathrm{S}_{\text {BET }}<60 \mathrm{~m}^{2} \mathrm{~g}^{-1}\right)$, N,P-doped non-porous carbon nanofibers with C-O-P groups and pyrrole-like nitrogen, exhibited a high specific capacitance $224 \mathrm{~F} \mathrm{~g}^{-1}$, which was related to a synergistic effect in which $\mathrm{N}$-groups delivered a high pseudocapacitance while phosphorus contributed to enhancing the capacitive processes by increasing the wettability. The performance of EC based on N,P-co-doped graphene (G) monoliths was checked by Wen et al. (2016). N/P-Gs were synthesized with different doping level of $\mathrm{N}$ and $\mathrm{P}$, leading to a stable $\mathrm{EC}$ at $1.6 \mathrm{~V}$ in $\mathrm{H}_{2} \mathrm{SO}_{4}$ and delivering a high energy density value of $11.33 \mathrm{~W} \mathrm{~h} \mathrm{~kg}^{-1}$. This value is higher than those obtained from $\mathrm{N}$-doped graphene in the literature (Lee Y. H. et al., 2013), showing that phosphorus groups combined with nitrogen groups cause a synergistic effect. The effect of other co-doping processes (N-S, B-N, etc.) on the electrochemical behavior of the dopedcarbon materials has been reported, although studies of the performance of the capacitor in two-electrode cells are scarce (Guo and Gao, 2009; Konno et al., 2010; Tomko et al., 2011; Zhang et al., 2014; Chen C. et al., 2015; Xiang et al., 2017). In view of the above summary on the effect of heteroatoms, it can be concluded that the approach of introducing heteroatoms into the carbon network is a promising method to enhance the energy density in ECs.

\section{NCMs Composites}

NCMs have been combined with other electroactive materials such as metal oxides or conducting polymers (CPs) that contribute to the storage of energy through pseudocapacitive processes.

It is well-known that the pseudocapacitance produced by faradic reactions in metal oxides leads to electrode materials with much higher capacitances than those of NCMs. Transition metal oxides $\left(\mathrm{RuO}_{2}, \mathrm{MnO}_{2}, \mathrm{~V}_{2} \mathrm{O}_{5}\right.$, etc.), spinel oxides $\left(\mathrm{NiCo}_{2} \mathrm{O}_{4}\right.$ or $\mathrm{MnCo}_{2} \mathrm{O}_{4}$ ) and $\mathrm{Ni} / \mathrm{Co}$ hydroxides (Demarconnay et al., 2011; Jiang et al., 2012; Wang et al., 2012; Augustyn et al., 2014) are among the most studied. Regarding $\mathrm{RuO}_{2}$-based materials, they show extraordinary gravimetric capacitance, making them interesting electrode materials for ECs. The first report about $\mathrm{RuO}_{2}$-based electrode material in ECs showed a high capacitance $\left(720 \mathrm{~F} \mathrm{~g}^{-1}\right)$ (Zheng and Jow, 1995). Since then, $\mathrm{RuO}_{2}$ has widely been studied for their use in ECs (Conway and Pell, 2003; Park et al., 2003; Ye et al., 2005b; Rakhi et al., 2011; Zhang et al., 2011; Huang et al., 2013; Xia et al., 2015). Shen et al. (2016) reported ECs based on $\mathrm{RuO}_{2}$ nanodots on graphene using ionic liquid as electrolyte, which displayed an energy density of $103 \mathrm{~W} \mathrm{~h} \mathrm{~kg}^{-1}$ with a potential window of $3.8 \mathrm{~V}$. Metal oxide nanoparticles on graphene were evaluated in alkaline medium by Rakhi et al. (2011) in a two-electrode cell, exhibiting an energy density value of $50.6 \mathrm{Wh} \mathrm{kg}^{-1}$ for $\mathrm{RuO}_{2} / \mathrm{G}$. According to these values of energy density, $\mathrm{RuO}_{2}$ composites are very good candidates as electrode materials, but their price and scarcity hinder their commercialization. At this point, $\mathrm{MnO}_{2}$ is an 
interesting alternative since ECs based on $\mathrm{MnO}_{2} / \mathrm{G}$ composites have already exhibited a high energy density value of $33.1 \mathrm{~W}$ $\mathrm{h} \mathrm{kg}^{-1}$ (Rakhi et al., 2011). The combination of $\mathrm{RuO}_{2}$ with inexpensive metal oxides (such as $\mathrm{TiO}_{2}, \mathrm{VO}_{\mathrm{x}}, \mathrm{MoO}_{3}$, and $\mathrm{SnO}_{2}$ ) has been also proposed (Takasu and Murakami, 2000; Sugimoto et al., 2002), leading to $\mathrm{RuO}_{2}$ composites with a larger SSA that can increase the electrochemical activity. Recently, $\mathrm{Ni}$ and $\mathrm{Co}$ oxides were evaluated as electrode materials for ECs because they have pseudocapacitance and high electrical conductivity that can also favor the capacitive processes (Faraji and Ani, 2014). In summary, metal oxide-modified NCMs can be considered as promising electrode materials because the faradic reactions and double layer contributions from the metal oxide, combined with the already explained properties of NCMs can lead to enhanced ECs performance (Chen et al., 2018; Lai et al., 2018).

Concerning CPs, polyaniline (PANI), polypyrrole (PPy), polythiophene (PTh), and poly(3,4-ethylenedioxythiophene) (PEDOT), are the most common ones and they have interesting properties that make them suitable materials for their use in ECs. These properties include pseudocapacitance from its redox activity, high electrical conductivity and large electrochemical stability voltage, among others (Snook et al., 2011; Ghosh and Lee, 2012; Wang et al., 2012; Vlad et al., 2016). However, the main drawbacks for their implementation in ECs are their difficult processability and poor mechanical stability of the electrodes due to the changes of volume occurring during the doping/de-doping processes. All this makes necessary the combination of CPs with other materials in order to produce adequate electrodes for ECs. In this sense, NCMs are considered interesting supports to mitigate volume changes and their combination with the most common CPs have already been reported (Snook et al., 2011; Bose et al., 2012; Wang et al., 2012). PPy and PANI are the most studied due to their easy synthesis, environmental stability and low cost (Park and Park, 2002; Gupta and Miura, 2006; Mini et al., 2011). Gupta and Miura (2006) reported SWCNT/PANI composites as excellent electrode material, obtaining a capacitance value of $485 \mathrm{~F} \mathrm{~g}^{-1}$. Mini et al. (2011) synthesized a PPy thin film on graphene by electropolymerization, obtaining an extraordinary specific capacitance of $1,510 \mathrm{~F} \mathrm{~g}^{-1}$. As can be seen, the combination of CPs and NCMs is an interesting approach to increase the energy density values through the pseudocapacitance contribution from CPs. In addition, the poor mechanical properties of CPs are improved, which in turn results in an increase in the cycle life of the ECs.

\section{Electrolytes}

The electrolytes (salt/solvent) used in ECs can be divided into four groups: organic, aqueous, ionic liquids and solid-state polymer. Organic electrolytes are the most used in commercial ECs because of their high potential stability window (2.5$3.2 \mathrm{~V}$ ). The most used organic electrolyte consists of salts such as triethylmethylamoniumtetrafluoroborate $\left(\mathrm{TEMABF}_{4}\right)$ or tet raethylammoniumtetrafluroborate $\left(\mathrm{TEABF}_{4}\right)$ in acetonitrile or propylene carbonate as solvents. However, organic electrolytes present disadvantages such as a high cost, low electrical conductivity, toxicity, and flammability. On the contrary, aqueous electrolytes $\left(\mathrm{H}_{2} \mathrm{SO}_{4}, \mathrm{KOH}\right.$, or $\left.\mathrm{Na}_{2} \mathrm{SO}_{4}\right)$ do not have these shortcomings and, even though they exhibit higher specific capacitance and electrical conductivity than those obtained in organic electrolytes, their main drawback is their lower potential stability window $(<1.23 \mathrm{~V})$. For this reason, there is an increasing interest in the development of new electrolytes, which may circumvent the shortcomings showed by both organic and aqueous electrolytes. Balducci (2016) indicated the aspects to be considered in the electrolyte design such as large electrochemical stability, high conductivity, low viscosity, high chemical stability, high boiling point and so forth. Ionic liquids, which are composed by an organic cation and an inorganic/organic anion, encompass some of the considerations mentioned above such as low flammability, insignificant volatility, high stability and higher potential stability window (>4 V) (Zhong et al., 2015; Martins et al., 2018). The most studied ILs in ECs are pyrrolidinium and imidazolium cations coupled with anions such as $\mathrm{PF}_{6}^{-}, \mathrm{BF}_{4}^{-}$, or TFSI ${ }^{-}$. Regarding solid polymer electrolyte, it has both the role of ionic medium and separator. There are many types of solid polymer electrolytes, but the research community has recently been focused on gel polymer electrolytes. They consist of a polymer such as poly(vinylalcohol) (PVA), or polyethylene oxide (PEO) among others, which is dissolved in aqueous solutions $\left(\mathrm{H}_{2} \mathrm{SO}_{4}, \mathrm{H}_{3} \mathrm{PO}_{4}\right.$, etc.) (Choudhury et al., 2009; Fei et al., 2014) and, even though these electrolytes have been claimed as a promising alternative to be used in supercapacitors, they have only been used in specific electronic devices up to date.

Despite the remarkable development in the design of electrolytes so far, strong efforts are being devoted to increase their electrical conductivity and their electrochemical stability, which are key factors in the enhancement on energy density of the ECs.

\section{Device Configuration}

The most common classification is based on the composition of electrode material and, although there are some discrepancies to set the borderline among different types of ECs, three configurations are differentiated as follows: (i) symmetric, (ii) asymmetric, and (iii) hybrid. The main features for each configuration will be established in this section along with some specific examples reported in the literature.

\section{Symmetric ECs}

This configuration consists of two identical electrodes in terms of chemical composition and mass, regardless of whether both electrodes display a purely capacitive or pseudocapacitive behavior. Most of the symmetric ECs are based on AC in both organic and aqueous electrolytes. Recently, there is an increasing interest in the use of aqueous electrolytes instead of organic ones. The main approach is based on increasing their low working voltage, which is limited by the potentials of water decomposition. To do that, some authors have evaluated the stability of neutral electrolytes such as $\mathrm{Na}_{2} \mathrm{SO}_{4}$ or $\mathrm{Li}_{2} \mathrm{SO}_{4}$ (Bichat et al., 2010; Demarconnay et al., 2010; Chen et al., 2018). Bichat et al. (2010) demonstrated that an AC-based symmetric EC using $\mathrm{Na}_{2} \mathrm{SO}_{4}$ as electrolyte displayed a high stability voltage of 
$1.6 \mathrm{~V}$ and an interesting performance. Later, Gao et al. (2012) reported that AC-based symmetric capacitor using $\mathrm{Li}_{2} \mathrm{SO}_{4}$ as electrolyte exhibited a high cell voltage of $1.9 \mathrm{~V}$ and a good capacitance retention after 10,000 cycles. These high cell voltages are connected to the high overpotential of the negative electrode to electrochemical hydrogen evolution reaction. Therefore, it is essential to develop NCMs with high overpotential values for oxygen and hydrogen evolution reactions in order to broaden the cell voltage.

\section{Asymmetric ECs}

Asymmetric supercapacitors are composed of two different electrode materials, one of them with an essentially capacitive behavior, and the other one with pseudocapacitive processes. In addition, ECs based on the same electrode material and different active mass can also be considered as asymmetric configuration (Chae and Chen, 2012; Piñeiro-Prado et al., 2016), regardless of the electrochemical behavior of the electrode material, which can be purely capacitive or pseudocapacitive. The main advantage of these systems is that a small mass balancing causes the unequalization of both positive and negative electrode capacitance values, allowing to expand the available stability potential window for both electrodes and to reach the maximum operating cell voltage.

A wide variety of electrode materials has been used to build asymmetric ECs, although the most common are based on metal oxides, CPs or their composites with NCMs (Demarconnay et al., 2011; Fan et al., 2011; Ou et al., 2015; Kim et al., 2017; Li et al., 2018). Demarconnay et al. (2011) evaluated the maximum cell voltage for an aqueous asymmetric EC constituted by $\mathrm{MnO}_{2} / \mathrm{AC}$, showing a noticeable stability at $2 \mathrm{~V}$. Recently, $\mathrm{Ou}$ et al. (2015) reported an asymmetric capacitor based on Na-doped $\mathrm{MnO}_{2}$ and $\mathrm{AC}$, that had a cell voltage up to $2.4 \mathrm{~V}$. Chen et al. (2011) studied CNT- $\mathrm{V}_{2} \mathrm{O}_{5} / \mathrm{AC}$-based asymmetric EC in organic medium, leading to a high-density energy of $40 \mathrm{~W}$ $\mathrm{h} \mathrm{kg}^{-1}$. Regarding asymmetric ECs based on CPs, Frackowiak et al. (2006) studied the composites of CNT with CPs (PANI, PPy, PEDOT) in a two-electrode cell, which presented good capacitance values and cell voltages up to $1.8 \mathrm{~V}$. Zhou et al. (2014) indicated that ECs based on aligned CNTs and PEDOT/CNTs in organic medium can reach $4 \mathrm{~V}$ of voltage and deliver an outstanding volumetric energy of $82.8 \mathrm{~W} \mathrm{~h} \mathrm{~L}^{-1}$.

In summary, this configuration is very promising to enhance the energy density of the capacitors since a suitable selection of electrode materials and a rigorous study of their electrochemical stability limits, will allow us to exploit the entire operating voltage by optimization of mass ratio or composition (Peng et al., 2010; Chae and Chen, 2012).

\section{Hybrid Supercapacitors}

Hybrid ECs are those devices that combine a supercapacitortype electrode and a battery-type one (Chen Y. M. et al., 2015; $\mathrm{Yu}$ et al., 2016). Several hybrid systems, such as $\mathrm{AC} / \mathrm{MnCo}_{2} \mathrm{~S}_{4}$, $\mathrm{AC} / \mathrm{NiCo}_{2} \mathrm{~S}_{4}, \mathrm{AC} / \mathrm{Co}_{3} \mathrm{~S}_{4}$ and so on, have been studied. The $\mathrm{CPs} / \mathrm{NCM}$ composites as electrodes are also considered by some researchers as battery-type because a large fraction of the charge is stored by faradic reactions. Thus, ECs based on NCMs as negative electrode (capacitor-type) and CPs/NCMs as positive electrode (battery-type) could be classified within this group. Other devices considered as hybrid supercapacitors used redox active electrolyte such as iodide/iodine, bromide/bromine or $\mathrm{Fe}^{3+} / \mathrm{Fe}^{2+}$ (Frackowiak et al., 2014; Ma et al., 2014; Zhong et al., 2015; Ren et al., 2017). Therefore, the faradic contribution comes from both the electrolyte and the electrode material. For instance, Lota and Frackowiak (2009) reported a supercapacitor consisting of carbon electrodes and iodine-based electrolyte that showed a capacitance value of $125 \mathrm{~F} \mathrm{~g}^{-1}$ at $50 \mathrm{~A} \mathrm{~g}^{-1}$ and a good stability after 10,000 cycles. Undoubtedly, the most important hybrid systems are the ion-lithium capacitors that are based on activated carbon as positive electrode and an intercalation electrode material (graphite, $\mathrm{Li}_{4} \mathrm{Ti}_{5} \mathrm{O}_{12}$, etc.) as negative electrode to host lithium ions. LICs can store 5-10 times more energy than conventional supercapacitors and are capable of delivering high power density for a long time (Naoi et al., 2012; Sivakkumar and Pandolfo, 2012; Han et al., 2018).

Along this section, many aspects of how to enhance the EC performance were dealt. Not only the synthesis of NCMs was described, but also different EC configurations were addressed to enhance the EC performance. However, the comparison between different ECs becomes the object of controversy. This is because the important parameters such as power or energy density values are measured at different experimental conditions. In spite of this, a table that summarizes some representative examples of EC based on NCMs can be useful to extract conclusions (see Table 1).

\section{ENHANCEMENT OF ELECTROCHEMICAL CAPACITORS PERFORMANCE}

This section is dedicated to review some studies related with ECs, which were performed in our research group in order to improve the ECs performance following some of the different approaches mentioned previously. This section is divided in the following four parts:

\section{ECs Based on N-doped Porous Carbon: Stabilizing Effect of $\mathbf{N}$-groups}

The role of the nitrogen-functional groups on the electrochemical performance of $\mathrm{N}$-containing porous carbons used as electrode material in ECs has been studied in detail [77]. For this purpose, activated carbon fibers (ACF) were used as carbon source material because of the lower tortuosity of its porosity network compared to other carbon materials. Aniline monomer was adsorbed on the ACF before chemical polymerization to polyaniline which was subsequently carbonized. The ordered structure of the $\mathrm{N}$-containing precursor (i.e., polyaniline) results in the formation of specific type of nitrogen groups after carbonization, which could play a pivotal role in the final performance of these materials used in energy storage applications (Snook et al., 2011; Kim and Park, 2012).

Regarding the preparation of PANI-ACF samples, they were synthesized by a chemical polymerization method described in previous works (Bleda-Martínez et al., 2008a; Salinas-Torres et al., 2012, 2013), obtaining a polyaniline thin film within 
TABLE 1 | Overview of EC based on NCMs.

\begin{tabular}{|c|c|c|c|c|c|}
\hline Material & Synthesis & Power & Energy & Remarks & References \\
\hline $\begin{array}{l}\text { Zeolite templated carbon }(+) \\
\text { activated carbon }(-)\end{array}$ & $\begin{array}{l}\text { CVD (+) } \\
\text { and } \mathrm{KOH} \text { activation }(-)\end{array}$ & - & $24.5 \mathrm{Wh} \mathrm{kg}^{-1}$ & $\begin{array}{l}\text { Asymmetric } \\
1.0 \mathrm{M} \mathrm{H}_{2} \mathrm{SO}_{4} \mathrm{~V}=1.4 \mathrm{~V}\end{array}$ & Nueangnoraj et al., 2014 \\
\hline Microporous carbon & $\mathrm{KOH}$ activation & $0.7 \mathrm{~kW} \mathrm{~kg}^{-1}$ & 10.9 $\mathrm{Wh} \mathrm{kg}^{-1}$ & $\begin{array}{l}\text { Asymmetric } \\
0.5 \mathrm{M} \mathrm{Na}_{2} \mathrm{SO}_{4} \mathrm{~V}=1.8 \mathrm{~V}\end{array}$ & Piñeiro-Prado et al., 2016 \\
\hline Zeolite templated carbon & CVD & $23 \mathrm{~kW} \mathrm{~kg}^{-1}$ & $5.9 \mathrm{Wh} \mathrm{kg}^{-1}$ & $\begin{array}{l}\text { Symmetric } \\
1 \mathrm{M} \mathrm{H}_{2} \mathrm{SO}_{4}\end{array}$ & Mostazo-López et al., 2018 \\
\hline $\mathrm{N}$-Zeolite templated carbon & CVD & $98 \mathrm{~kW} \mathrm{~kg}^{-1}$ & $7.5 \mathrm{Wh} \mathrm{kg}^{-1}$ & $\begin{array}{l}\text { Symmetric } \\
1 \mathrm{M} \mathrm{H}_{2} \mathrm{SO}_{4}\end{array}$ & Mostazo-López et al., 2018 \\
\hline graphene mesosponge & CVD & $10 \mathrm{~kW} \mathrm{~kg}^{-1}$ & $60 \mathrm{Wh} \mathrm{kg}^{-1}$ & $\begin{array}{l}\text { Symmetric } \\
1 \mathrm{M} \mathrm{Et}_{3} \mathrm{MeNBF}_{4} / \mathrm{PC} \\
\mathrm{V}=4.4 \mathrm{~V}\end{array}$ & Nomura et al., 2019 \\
\hline N-Carbon Nanosheets & $\mathrm{N}$-doping of $\mathrm{GO}$ & $0.111 \mathrm{~kW} \mathrm{~kg}^{-1}$ & 86.6 Wh kg $\mathrm{Wh}^{-1}$ & $\begin{array}{l}\text { Symmetric } \\
\text { BMIMPF }_{6} \\
\mathrm{~V}=4.0 \mathrm{~V}\end{array}$ & Li et al., 2017 \\
\hline $\begin{array}{l}\text { N,S co-doped carbon } \\
\text { nanospheres }\end{array}$ & $\begin{array}{l}\text { pyrolysis of polypyrrole } \\
(\mathrm{PPy}) \text { and }\left(\mathrm{NH}_{4}\right)_{2} \mathrm{~S}_{2} \mathrm{O}_{8}\end{array}$ & $0.100 \mathrm{~kW} \mathrm{~kg}^{-1}$ & 18.1 Wh kg-1 & $\begin{array}{l}\text { Symmetric } \\
6 \mathrm{M} \mathrm{KOH} \\
\mathrm{V}=4.0 \mathrm{~V}\end{array}$ & Xin et al., 2018 \\
\hline $\begin{array}{l}\text { N,B co-doped } \\
\text { porous carbon nanowires }\end{array}$ & $\begin{array}{l}\text { Electrodeposition of } \\
\mathrm{PANI} / \mathrm{H}_{3} \mathrm{BO}_{3} \\
\text { /carbonization }\end{array}$ & $0.200 \mathrm{~kW} \mathrm{~kg}^{-1}$ & 22.7 $\mathrm{Wh} \mathrm{kg}^{-1}$ & $\begin{array}{l}\text { Symmetric } \\
1.0 \mathrm{M} \mathrm{H}_{2} \mathrm{SO}_{4} \\
\mathrm{~V}=1.6 \mathrm{~V}\end{array}$ & Zhao and Xie, 2018 \\
\hline N-doped activated carbon & $\begin{array}{l}\text { Organic routes at mild } \\
\text { conditions }\end{array}$ & $0.0612 \mathrm{~kW} \mathrm{~kg}^{-1}$ & 14.5 $\mathrm{Wh} \mathrm{kg}^{-1}$ & $\begin{array}{l}\text { Symmetric } \\
1.0 \mathrm{M} \mathrm{H}_{2} \mathrm{SO}_{4} \mathrm{~V}=1.4 \mathrm{~V}\end{array}$ & Mostazo-López et al., 2016 \\
\hline N-doped carbon nanocages & $\begin{array}{l}\text { MgO template with } \\
\text { pyridine/benzene }\end{array}$ & $0.250 \mathrm{~kW} \mathrm{~kg}^{-1}$ & 10.9 $\mathrm{Wh} \mathrm{kg}^{-1}$ & $6 \mathrm{M} \mathrm{KOH}$ & Zhao J. et al., 2015 \\
\hline $\mathrm{CP}$ on aligned CNTs & CVD & $269.4 \mathrm{~kW} \mathrm{~kg}^{-1}$ & 170.7 Wh kg-1 & $\begin{array}{l}\text { Asymmetric } \\
2.0 \mathrm{M} \mathrm{BMIBF}_{4} / \mathrm{PC} \\
\mathrm{V}=4.0 \mathrm{~V}\end{array}$ & Zhou et al., 2014 \\
\hline $\mathrm{CNT}-\mathrm{V}_{2} \mathrm{O}_{5} / \mathrm{AC}-$ & hydrothermal process & $0.210 \mathrm{~kW} \mathrm{~kg}^{-1}$ & $40 \mathrm{Wh} \mathrm{kg}^{-1}$ & $\begin{array}{l}\text { Asymmetric } \\
1 \mathrm{M} \mathrm{LiClO4/PC} \\
\mathrm{V}=2.7 \mathrm{~V}\end{array}$ & Chen et al., 2011 \\
\hline $\begin{array}{l}\text { Metal hidroxide } \\
\text { Nanosheets@N-doped CNT }\end{array}$ & CBD & $0.966 \mathrm{~kW} \mathrm{~kg}^{-1}$ & $71 \mathrm{Wh} \mathrm{kg}^{-1}$ & $\begin{array}{l}\text { Asymmetric } \\
2 \mathrm{M} \mathrm{KOH}\end{array}$ & Zhang et al., 2019 \\
\hline
\end{tabular}

the porosity of the ACF with an estimated average thickness of about $0.5 \mathrm{~nm}$. Three different concentrations of aniline monomer were used for aniline adsorption (10, 30, and $70 \mathrm{mM}$ ) and a subsequentpolymerization step was performed. Finally, these three different PANI/ACF samples were carbonized at 600 and $800^{\circ} \mathrm{C}$ by following the method described elsewhere (Salinas-Torres et al., 2015). Porous texture of all samples was characterized by physical adsorption of $\mathrm{N}_{2}$ at $-196{ }^{\circ} \mathrm{C}$, leading to Type I isotherms (typical of microporous solids) and showing an important decrease in the $\mathrm{N}_{2}$ uptake after PANI loading because of the formation of polyaniline thin film over the surface of the fibers. A small increase in $\mathrm{N}_{2}$ uptake at low pressures happened after carbonization, although $\mathrm{S}_{\mathrm{BET}}$ of pristine ACF was not completely recovered.

From the XPS results, it was observed that nitrogen content for ACF/PANI samples dropped after their carbonization. As an example, Figure 1A shows the deconvolution of N1s spectra for sample ACF30 and after carbonization. It can be seen some differences between ACF30 and their carbonized counterparts. On the one hand, ACF30 presented the main peak at around $399.5 \mathrm{eV}$ corresponding to neutral amine group (RaymundoPiñero et al., 2002) and a small peak is located at $402 \mathrm{eV}$, which is associated to oxidized $\mathrm{N}$ species. On the other hand, ACF30-600 exhibited two peaks at different binding energies in comparison to ACF30. One peak appeared at around $398.7 \mathrm{eV}$ related to pyridine groups, while the second peak is centered at $400.5 \mathrm{eV}$ corresponding to pyrrole and pyridone groups (RaymundoPiñero et al., 2002).

As the temperature increased, both peaks in ACF30-800 become much sharper than those of ACF30-600. The first peak appeared at $398.7 \mathrm{eV}$ and the second shifted to higher binding energies $(400.7 \mathrm{eV})$, which was mainly assigned to pyrrole/pyridone and quaternary $\mathrm{N}$ groups. The evolution of nitrogen-functional groups upon heat treatment is in agreement with the carbonization mechanism proposed for PANI (Rozlívková et al., 2011; Kuroki et al., 2013).

After that, symmetric ECs based on these samples were assembled using an $\mathrm{Al} / \mathrm{Mg}$-body two-electrode cell and were evaluated in organic electrolyte $(1 \mathrm{M}$; TEMA-BF $4 / \mathrm{PC})$ by a floating test, keeping 3.2 V for $100 \mathrm{~h}$ (see Table 2).

First, a rate performance study was carried out for all samples and it was noticed that the capacitance values dropped as the current density increases. This decay was sharper in ACF/PANI samples than in the carbonized ones because PANI deposited inside the porosity may hamper the mass transfer rate. 

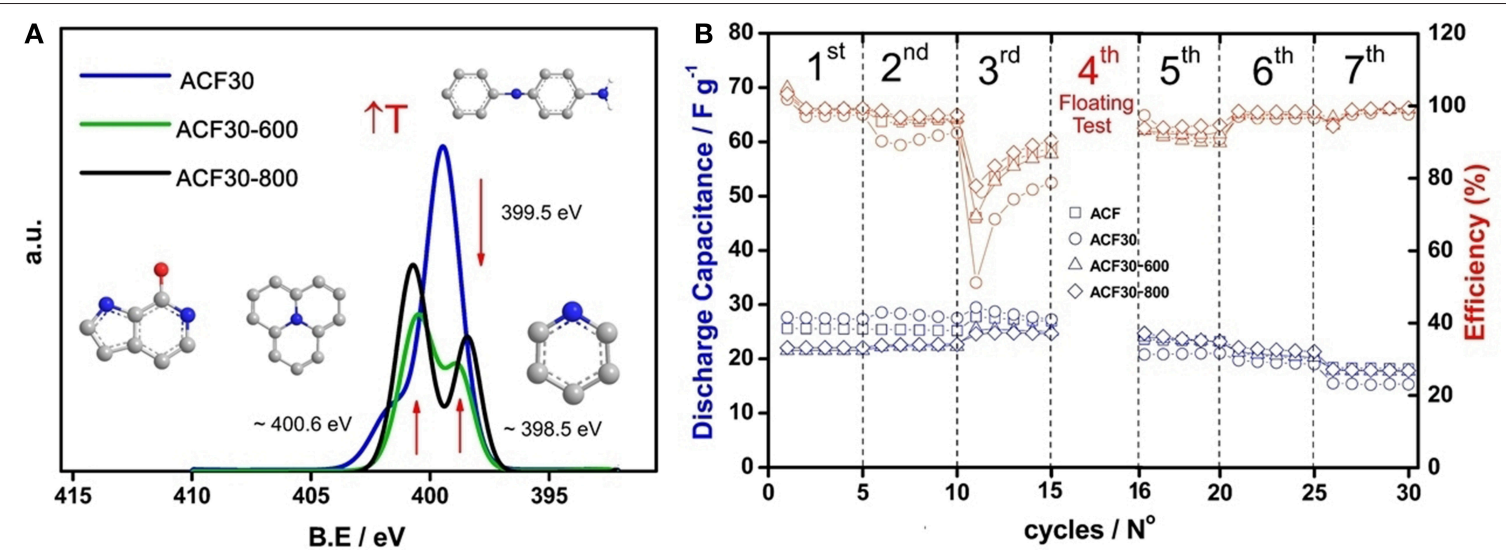

FIGURE 1 | (A) Deconvoluted N1s XPS spectra of ACF30, ACF30-600, and ACF30-800. (B) Capacitance performance and efficiency for symmetric ECs based on ACF, ACF30, ACF30-600, and ACF30-800 samples. Electrolyte: 1M TEMA-BF4/PC.

TABLE 2 | Electrochemical conditions and temperature during the durability test.

\begin{tabular}{lcccc}
\hline Steps & $\mathbf{T} /{ }^{\circ} \mathbf{C}$ & $\mathbf{V} / \mathbf{V}$ & $\mathbf{j} / \mathbf{m A ~ g}^{-\mathbf{1}}$ & $\mathbf{N}^{\circ}$ Cycles \\
\hline 1st & 40 & $0-2.5 \mathrm{~V}$ & 80 & 1 st-5th \\
2nd & 70 & $0-2.5 \mathrm{~V}$ & 80 & 6 th-10th \\
3rd & 70 & $0-3.2 \mathrm{~V}$ & 80 & 11 th-15th \\
4th & 70 & $3.2 \mathrm{~V}^{*}$ & - & - \\
5th & 70 & $0-3.2 \mathrm{~V}$ & 80 & 16 th-20th \\
6th & 70 & $0-2.5 \mathrm{~V}$ & 80 & 21 th-25th \\
7th & 40 & $0-2.5 \mathrm{~V}$ & 80 & 26 th-30th
\end{tabular}

${ }^{*}$ Hold at $3.2 \mathrm{~V}$ for $100 \mathrm{~h}$.

Both coulombic efficiency and capacitance for all symmetric ECs were obtained from the floating test. Figure 1B displays the evolution of both capacitance and efficiency during the durability test for symmetric ECs that are based on sample ACF30 and their carbonized counterparts under galvanostatic conditions. ACF-based symmetric EC was also plotted for comparison purposes. At the beginning, coulombic efficiency remained almost constant for all samples. However, the efficiency for ACF30 sample, which had not been carbonized, experienced a moderate fall after increasing the temperature at $70^{\circ} \mathrm{C}$ because of the polyaniline degradation.

Regarding the discharge capacitance, all samples followed the same trend as coulombic efficiency during the two initial steps. Then, efficiency decreased drastically after increasing the cell voltage up to $3.2 \mathrm{~V}$ because of the severe conditions applied, which triggered the decomposition of electrolyte and electrode material, exhibiting the strongest decomposition for ACF30 (non-carbonized sample). At this step, the capacitance diminished slightly for the pristine ACF and ACF30, while the values for the carbonized ones remained constant. After the floating test, it was observed that significant changes happened in terms of the capacitance; ACF30 presented the lowest value, likely due to polyaniline (electrode material) and TEMA- $\mathrm{BF}_{4} / \mathrm{PC}$ (electrolyte) degradation. However, carbonized samples and pristine ACF presented the same

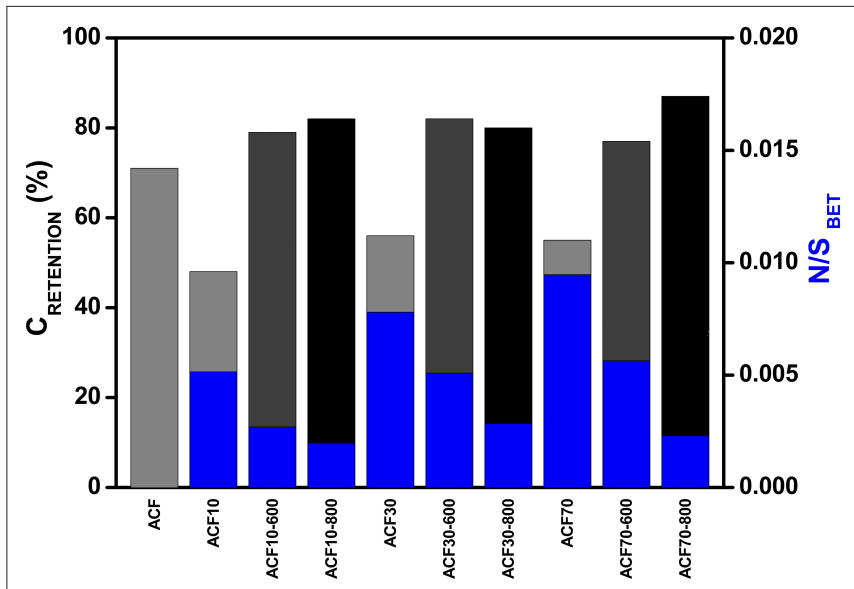

FIGURE 2 | Effect of the nitrogen amount on the capacitance retention (C/Co).

values in spite of the fact that ACF possesses nearly two-fold SSA as compared to carbonized ones. Thus, the durability test revealed that there was an effect of the nitrogenfunctional groups on the capacitance performance. As it was mentioned in the previous section, the insertion of nitrogen into the carbon network enhances the electrical conductivity, the electron transfer rate and improves the stability of the electrode material, decreasing the electrolyte decomposition rate.

In order to elucidate the effect of the $\mathrm{N}$-functional groups on the performance of the $\mathrm{N}$-containing materials, electrochemical characterization, SSA obtained from $\mathrm{N}_{2}$ adsorption isotherms and XPS data were taken into account. Figure 2 shows the capacitance retention and nitrogen amount normalized by SSA for all samples. It can be seen that carbonized samples exhibited the highest capacitance retention values, even better than pristine ACF, while ACF/PANI samples showed lower capacitance retention values despite their higher nitrogen content. According to XPS results, PANI- containing ACF presented mainly amine 
TABLE 3 | Porous texture and surface chemistry characterization of all samples.

\begin{tabular}{|c|c|c|c|c|c|}
\hline Sample & $\mathrm{S}_{\mathrm{BET}} / \mathrm{m}^{2} \mathrm{~g}^{-1}$ & $\mathrm{~V}_{\mathrm{DR}} \mathrm{N}_{2} / \mathrm{cm}^{3} \mathrm{~g}^{-1}$ & $\mathrm{~V}_{\mathrm{DR}} \mathrm{CO}_{2} / \mathrm{cm}^{3} \mathrm{~g}^{-1}$ & $\mathrm{CO} / \mu \mathrm{mol} \mathrm{g}-1$ & $\mathrm{CO}_{2} / \mu \mathrm{mol} \mathrm{g}^{-1}$ \\
\hline$A C$ & 3,310 & 1.20 & 0.76 & 2,250 & 660 \\
\hline $\mathrm{ACH}$ & 3,180 & 1.10 & 0.70 & 495 & 100 \\
\hline CAC & 995 & 0.45 & 0.41 & 660 & 320 \\
\hline
\end{tabular}

groups while carbonized samples showed pyridine and positively charged nitrogen species (pyrrole and quaternary $\mathrm{N}$ ). Therefore, amine groups present in PANI-containing ACF samples favor the propylene carbonate-ring opening because of their nucleophilic character (Kinage et al., 2011). The carbonate-ring opening is also enhanced by oxygen groups as reported by Cazorla-Amorós et al. (2010). For this reason, ACF showed lower performance than those obtained from carbonized samples, whose $\mathrm{N}$ functionalities provide a stabilizing effect on both the electrolyte and the electrode material. In addition, another parameter obtained from the floating test was the integrated-leakage current, which is related to electrochemical decomposition of the electrolyte or electrode. The smallest integrated-leakage current was displayed by the carbonized samples, confirming the stabilizing effect on the electrolyte or electrode. To conclude, it is demonstrated that specific nitrogen functional groups improve the supercapacitor performance by a remarkable stabilizing effect.

\section{AC/AC-Based Asymmetric EC: Opening the Operating EC Voltage}

Asymmetric ECs (in terms of mass configuration) were designed in order to widen the operating voltage using an aqueous electrolyte $\left(\mathrm{Na}_{2} \mathrm{SO}_{4}\right)$. Throughout this study, three activated carbons were used: a) ultraporous activated carbon (AC); b) the same one treated in $\mathrm{H}_{2}$ at $800^{\circ} \mathrm{C}(\mathrm{ACH})$; c) an activated carbon used in commercial ECs (CAC). $\mathrm{Na}_{2} \mathrm{SO}_{4}$ was selected because their overpotential for water decomposition is higher than those obtained from both acid and basic electrolytes. In contrast, the pseudocapacitive redox processes, which are associated to the surface chemistry, are mostly suppressed.

Table 3 compiles the porous texture and surface chemistry characterization for all electrode materials. $\mathrm{AC}$ and $\mathrm{ACH}$ displayed a higher $\mathrm{S}_{\mathrm{BET}}$ than CAC. Moreover, all samples showed a high development in the microporosity. CAC presented the narrowest PSD according to the difference between $\mathrm{V}_{\mathrm{DR}} \mathrm{N}_{2}$ and $\mathrm{V}_{\mathrm{DR}} \mathrm{CO}_{2}$. From surface chemistry results, $\mathrm{AC}$ presented the highest amount of oxygen groups, which evolved as $\mathrm{CO}$ type groups (carbonyls, quinone, and phenols) or $\mathrm{CO}_{2}$-type groups (mainly in carboxylic and lactones) during the thermal treatment (Román-Martínez et al., 1993; Figueiredo et al., 1999; Boehm, 2002). The amount of evolving groups dropped for $\mathrm{ACH}$ because most of them were removed by hydrogen treatment, while CAC sample also presented a lower amount of CO-evolving groups than $\mathrm{AC}$. The quantity of $\mathrm{CO}_{2}$-evolving groups for $\mathrm{AC}$ was twice of that for $\mathrm{CAC}$, which were identified mainly as carboxylic groups.
All activated carbons were characterized by cyclic voltammetry $(\mathrm{CV})$ in a three-electrode cell to evaluate their capacitance and the maximum stability potential window in a neutral electrolyte $\left(0.5 \mathrm{M} \mathrm{Na}_{2} \mathrm{SO}_{4}\right)$ (Fic et al., 2012). The carbon electrodes were prepared with a thickness of $200-300 \mu \mathrm{m}$ that is similar to the values used in commercial supercapacitors. It is important to note that thickness is a pivotal parameter in the final performance of ECs (Stoller and Ruoff, 2010). The voltammogram for AC exhibited a quasi-rectangular shape related to the electric double layer formation in almost the whole potential window (Figure 3). During the negative-going scan, it can be seen that the reduction process appeared at $-0.9 \mathrm{~V}$, which corresponds to the hydrogen evolution reaction (Bleda-Martínez et al., 2008b), while during the positive-going scan, the oxidation of the carbon material did not become important up to potentials close to $0.7 \mathrm{~V}$. At this point, the degradation would be severe if the potential remained constant for a long time.

Regarding $\mathrm{ACH}$ and $\mathrm{CAC}$, both samples showed electrochemical behavior similar to AC sample. However, in the case of $\mathrm{ACH}$, the hydrogen evolution reaction shifted to more negative potential values and capacitance values were lower than AC because of the increased hydrophobic character produced by the hydrogen treatment. CAC sample also displayed lower values of capacitance than AC.

It is well-known that the positive electrode is completely charged to the upper potential limit before the negative electrode reaches its negative potential limit in symmetric ECs (Peng et al., 2010). Therefore, the design and optimization of an asymmetric capacitor allow us to widen the voltage without affecting the stability of both electrolyte and electrode material. Briefly, the methodology for optimization consisted on assessing the potential limits and the capacitance for both positive electrode and negative one, which must be determined from open circuit potential $\left(\mathrm{E}_{\mathrm{OCP}}\right)$ to the upper potential limit and the lower one, respectively. Then, the mass of one of the electrodes is fixed, while the mass of the second electrode is obtained using Equation (4) (Peng et al., 2010; Chae and Chen, 2012).

$$
Q=C_{S P+} \cdot w_{+} \cdot \Delta V_{+}=C_{S P-} \cdot w_{-} \cdot V_{-}
$$

Where $\mathrm{w}_{\mathrm{i}}$ is the weight of the electrode, $\mathrm{C}_{\mathrm{SPi}}$ is the gravimetric capacitance of the electrode in the stability potential window and the $\Delta V_{i}$ is the potential window used and is equal to $E_{i^{-}}$ E $\mathrm{OCP}$. Therefore, after fixing $\Delta \mathrm{V}_{+}$and $\Delta \mathrm{V}_{-}$from the threeelectrode cell characterization, and assuming that the capacitor is completely charged, the mass ratio of the electrodes is determined as follows (Equation 5):

$$
w_{+} / w_{-}=C_{S P_{-}} \cdot\left|\Delta V_{-}\right| /\left(C_{S P+} \cdot\left|\Delta V_{+}\right|\right)
$$


Taking into account the potential stability windows and inherent specific capacitance values, asymmetric ECs were built using the carbon materials mentioned above in a two-electrode cell configuration. From the voltammograms of AC sample (Figure 3), it was extracted that the open circuit voltage was 0.2 vs. $\mathrm{Ag} / \mathrm{AgCl}$, while both the lower potential limit and the upper one were $-1 \mathrm{~V}$ and $0.8 \mathrm{~V}$ vs. $\mathrm{Ag} / \mathrm{AgCl}$, respectively. Then, the specific capacitance values from galvanostatic charge-discharge curves at the stability potential windows were determined, obtaining a value of $199 \mathrm{~F} \mathrm{~g}^{-1}$ in the range of -1 to $0.2 \mathrm{~V}$ and $131 \mathrm{~F} \mathrm{~g}^{-1}$ between 0.2 to $0.8 \mathrm{~V}(\Delta \mathrm{V}=1.8 \mathrm{~V})$. Finally, the mass ratio was 3 for $\mathrm{AC}$ using these capacitance values and the chosen stability potential windows. The same procedure was used for assembling asymmetric ECs based on $\mathrm{ACH}$ and CAC in the stability potential window of 1.7 and $2.0 \mathrm{~V}$, respectively.

Finally, asymmetric ECs were analyzed by $\mathrm{CV}$ and galvanostatic charge-discharge (GCD) curves to demonstrate the proper operation of the EC in the selected voltage. Figure 4 shows the Ragone plot for all asymmetric ECs before starting the durability test. It can be seen that the evolution of energy density as power density increases presented different behavior for each EC. AC-based EC showed the highest values of energy density at low power densities. However, its power performance was poorer than that of asymmetric CAC/CAC, which achieved a power density value of $3.8 \mathrm{~kW} \mathrm{~kg}^{-1}$ while the maximum power density for asymmetric $\mathrm{AC} / \mathrm{AC}$ was 2.3 $\mathrm{kW} \mathrm{kg}^{-1}$. Concerning the supercapacitor based on $\mathrm{ACH}$, its power density was also higher than that of $\mathrm{AC} / \mathrm{AC}$, despite the lowest energy density showed by $\mathrm{ACH} / \mathrm{ACH}$. A higher cell resistance was observed for asymmetric $\mathrm{AC} / \mathrm{AC}$ compared to asymmetric CAC/CAC. Taking into account that sample CAC has a narrower PSD compared to AC material, which would result in higher ion diffusion resistance inside the pore network, the lower power density for AC/AC capacitor can be due to the lower intrinsic conductivity of the electrode material, which is in agreement with the highest porosity development and higher oxygen content in AC sample. The improvement in the power density of $\mathrm{ACH} / \mathrm{ACH}$ compared to $\mathrm{AC} / \mathrm{AC}$ is then due to the enhancement of electrical conductivity in $\mathrm{ACH}$ sample as oxygen-functional groups were removed by hydrogen treatment (Bleda-Martínez et al., 2005).

Then, the durability test was performed. It consisted of 10,000 cycles of charge-discharge with a current density of $1 \mathrm{~A} \mathrm{~g}^{-1}$ at the maximum cell voltage suitable for each supercapacitor. From these GCD cycles, parameters related to the capacitor performance were obtained. The capacitance values decreased after 10,000 cycles for $\mathrm{AC} / \mathrm{AC}$ and $\mathrm{CAC} / \mathrm{CAC}$, although the highest drop occurred for the asymmetric AC/AC. Concerning asymmetric $\mathrm{ACH} / \mathrm{ACH}$, it would seem that the performance improved after the durability test, although it is not strictly true because in the first 2,000 cycles the capacitance increased up to $34 \mathrm{~F} \mathrm{~g}^{-1}$ from its initial capacitance value and then, it followed the same trend as AC and CAC. This phenomenon was attributed to the increase in the hydrophilic character of the $\mathrm{ACH}$ surface during the durability test due to the electrochemical generation of surface oxygen groups, which facilitate the electrolyte diffusion into the accessible porosity and the EDL formation.

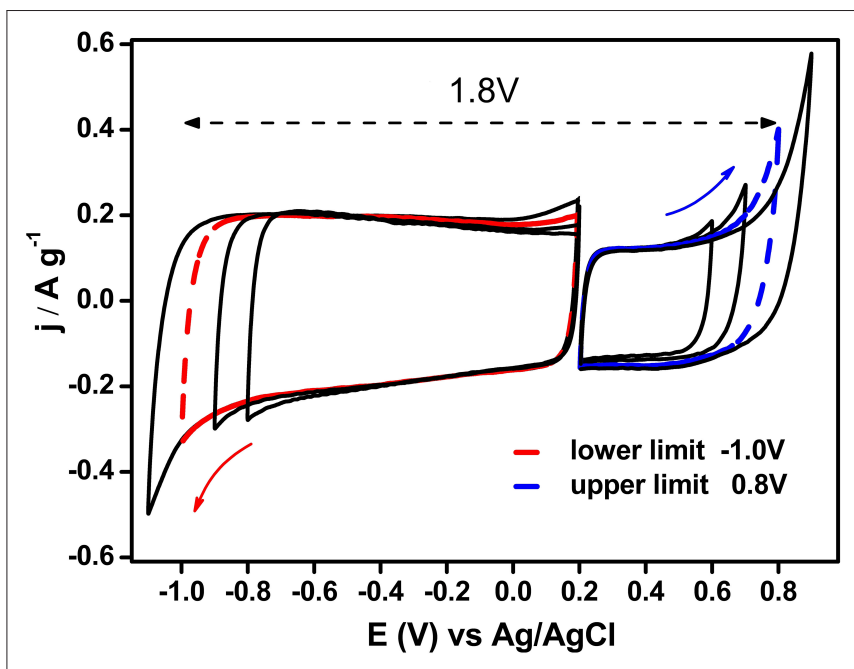

FIGURE 3 | Steady state voltammograms for AC sample from $\mathrm{E}_{\mathrm{OCP}}$ to both upper and lower limit potential values $\left(v=1 \mathrm{mV} \mathrm{s}^{-1} ; 0.5 \mathrm{M} \mathrm{Na}_{2} \mathrm{SO}_{4}\right)$.

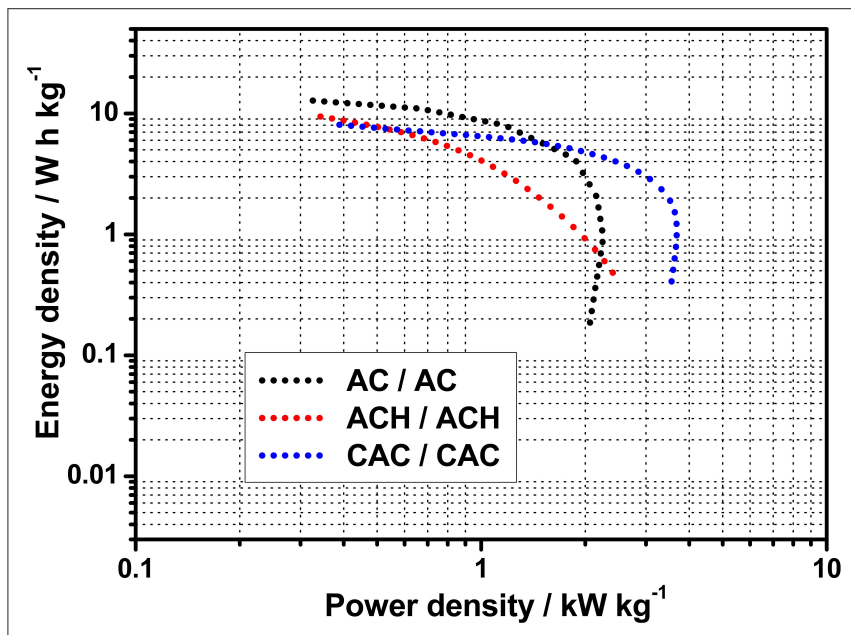

FIGURE 4 | Ragone plot for asymmetric supercapacitors of $A C(\Delta V=1.8 \mathrm{~V})$, $\mathrm{ACH}(\Delta \mathrm{V}=1.7 \mathrm{~V})$, and $\mathrm{CAC}(\Delta \mathrm{V}=2.0 \mathrm{~V})$ before durability test.

Regarding the energy and power density values, the asymmetric AC/AC capacitor displayed the highest energy density, while the best performance in terms of durability and power density was presented by asymmetric CAC/CAC, which is in agreement with the low resistance in the device as mentioned above. In addition, energy density values in volumetric basis were calculated because the comparison with other devices is more accurate. Energy densities were 7.3, 4.5, and $6.5 \mathrm{~W} \mathrm{~h} \mathrm{~L}^{-1}$ for $\mathrm{AC} / \mathrm{AC}, \mathrm{ACH} / \mathrm{ACH}$, and CAC/CAC capacitors, respectively. In conclusion, these values referred to unit volume exceed those obtained from symmetric supercapacitors based on activated carbons in aqueous electrolyte $\left(2.2 \mathrm{Wh} \mathrm{L}^{-1}\right)$ (Simon and Burke, 2008) and, in the case of asymmetric devices based on AC and CAC, they are close to those of symmetric supercapacitors in organic electrolyte $\left(7.6 \mathrm{Wh} \mathrm{L}^{-1}\right)$ 
(Simon and Burke, 2008) or commercial capacitors (3.2-7.2 $\mathrm{Wh} \mathrm{L}^{-1}$ ) (Simon and Burke, 2008; Gogotsi and Simon, 2011). Therefore, this strategy for designing asymmetric supercapacitors in greener and inexpensive electrolytes could be considered as an outstanding approach to boost the energy density value of the capacitors.

\section{Asymmetric Hybrid Supercapacitor: Enhancement of Capacitance}

The capacitance of the carbon-based electrodes can be enhanced using PANI as active material in the electrode together with an $\mathrm{AC}$ with high surface area. In this sense, the effect of polyaniline on the capacitance performance of an asymmetric EC in aqueous electrolyte $\left(\mathrm{H}_{2} \mathrm{SO}_{4}\right)$ was studied, in which an activated carbon with a high specific surface area (SSA) was used as negative electrode and an activated carbon fiber/PANI composite as the positive one.

The AC was not only selected for its high SSA $\left(\mathrm{S}_{\mathrm{BET}} \sim\right.$ $3,000 \mathrm{~m}^{2} \mathrm{~g}^{-1}$ ) but also for its suitable surface chemistry that contributed to the pseudocapacitance by faradic reactions from CO-type groups (Bleda-Martínez et al., 2006). Additionally, the electrochemical behavior observed in the voltammogram of the material revealed that during the negative-going scan (Figure 5A), the hydrogen evolution reaction did not appear up to potential values close to $-0.6 \mathrm{~V}$ vs. RHE. Therefore, the activated carbon selected possessed a high overpotential for hydrogen evolution reaction, indicating that this activated carbon has a remarkable stability at cathodic reduction potentials that makes it a good candidate as negative electrode. Furthermore, its specific capacitance from GCD experiments was $300 \mathrm{~F} \mathrm{~g}^{-1}$.

ACF/PANI composite was synthesized by chemical method described in a previous work (Salinas-Torres et al., 2012). The initial concentration of adsorbed monomer was established to have composites with $30 \mathrm{wt} . \%$ of aniline monomer inside the porosity. Both voltammograms of ACF and ACF/PANI samples are shown in Figure 5B and it can be observed that pristine ACF presented a weak peak centered at $0.60 \mathrm{~V}$ vs. RHE during the positive-going scan, which was assigned to surface oxygen groups (Wu et al., 2005). Regarding the ACF/PANI, several redox peaks related to the redox processes of polyaniline were observed, although these are not well-defined and are shifted compared to those obtained from pure polyaniline (Huang et al., 1986). In addition, defects mainly associated to quinone groups cannot be ruled out as consequence of the use of ammonium persulphate as oxidizing agent during the chemical synthesis, which could produce some polyaniline overoxidation (BledaMartínez et al., 2008a). Using this methodology, a thin film of polyaniline $(0.5 \mathrm{~nm})$ was deposited inside the porosity of the ACF as determined by SAXS (Salinas-Torres et al., 2012), and it did not hinder the ion diffusion inside the porosity considering that the pore size is still sufficiently large (Salinas-Torres et al., 2012). Finally, ACF/PANI sample displayed a specific capacitance of $200 \mathrm{~F} \mathrm{~g}^{-1}$, showing a $33 \%$ increase in capacitance compared to that for the pristine $\operatorname{ACF}\left(150 \mathrm{~F} \mathrm{~g}^{-1}\right)$.

Then, an asymmetric hybrid EC was built, which combined the high SSA and high overpotential for the hydrogen evolution reaction provided by the AC (with a relatively high SSA) and the pseudocapacitance (delivered by PANI deposited on ACF). Before building the asymmetric hybrid EC, the mass ratio of the electrode was optimized to enhance the performance as much as possible by using the mathematical method developed by Snook et al. (2009) to maximize the specific energy density in asymmetric ECS based on CPs. It consisted of fixing the specific capacitance values for both positive electrode $\left(\mathrm{C}_{+}\right)$and negative one $\left(\mathrm{C}_{-}\right)$, obtaining the maximum ratio of the active mass according to the Equation (6) and then, the mass of the positive electrode $\left(\mathrm{m}_{+}\right)$was fixed to calculate the mass of negative one $\left(\mathrm{m}_{-}\right)$by using Equation (7):

$$
\begin{aligned}
& \gamma_{\max }=\left(\frac{C_{-}}{C_{+}}\right)^{\frac{1}{2}} ; \\
& \gamma_{\max }=\frac{m_{(+)}}{m_{(-)}}
\end{aligned}
$$

Additionally, AC-based symmetric EC was assembled for comparison purposes and to demonstrate that asymmetric configuration can be a promising alternative to improve the energy density.

From GCD curves, $\mathrm{AC} \| \mathrm{AC}$ and $\mathrm{AC} \| \mathrm{ACF}$ supercapacitors exhibited a quasi-triangular shape, indicating that bulk faradic processes are negligible and, on the other hand, $\mathrm{AC} \| \mathrm{ACF} / \mathrm{PANI}$ showed a distorted triangular shape as consequence of the pseudofaradic processes of PANI. Moreover, the asymmetric $\mathrm{AC} \| \mathrm{ACF} / \mathrm{PANI}$ presented a good performance until $2 \mathrm{~A} \mathrm{~g}^{-1}$.

The evolution of specific capacitance with current density for all supercapacitors at the cell voltage of $1.6 \mathrm{~V}$ showed that the capacitance values for AC\|ACF/PANI supercapacitor are around $20 \%$ higher compared to $\mathrm{AC} \| \mathrm{ACF}$ in the entire range. The evolution of capacitance with the current density for all ECs reveals the ion diffusion problems which are more important with increasing the applied current. The decrease in capacitance is sharper for $\mathrm{AC} \| \mathrm{AC}$ supercapacitor than for both asymmetric capacitors. Moreover, the EC based on AC and ACF/PANI exhibited the best rate performance, which is associated to the faster kinetics for ACF electrodes compared to AC electrodes (Bleda-Martínez et al., 2010). Briefly, AC porosity possesses higher tortuosity than ACF, which explains this electrochemical behavior. Furthermore, the pivotal role of PANI in an asymmetric system was demonstrated because its presence improved the charge transfer and enhanced the total capacitance through the doping-dedoping processes of $\mathrm{CP}$. Additionally, the polyaniline thin film slowed down the oxidation of ACF because the oxygen evolution reaction is probably shifted at more positive potentials, given that the polyaniline oxidation happened at lower potential values.

The specific capacitance for all ECs diminished with cycling. The AC||ACF/PANI capacitor retained more than $80 \%$ of the initial value, obtaining an outstanding specific capacitance of $55.3 \mathrm{~F} \mathrm{~g} \mathrm{~g}^{-1}$ after 1,000 cycles. On the contrary, AC-based symmetric EC displayed the lowest specific capacitance after 1,000 cycles despite their initial capacitance, which exceeded the specific capacitance for the AC |ACF supercapacitor, indicating that the $\mathrm{AC}$ as electrode material suffered a faster degradation. 

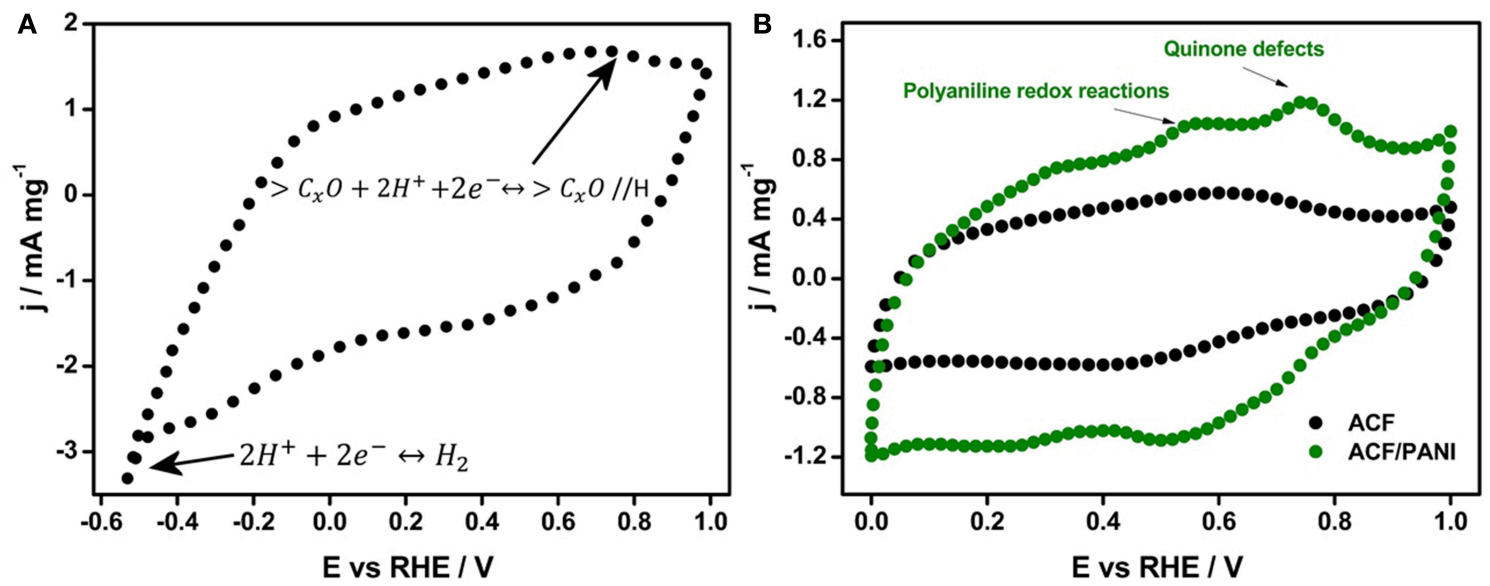

FIGURE 5 | Steady state cyclic voltammograms of: (A) AC (negative electrode) and (B) ACF/PANI (positive electrode) and pristine $\mathrm{ACF}$ in $0.5 \mathrm{M} \mathrm{H}_{2} \mathrm{SO}_{4}$. $\mathrm{Scan}$ rate: $5 \mathrm{mV} \mathrm{s}^{-1}$. Three-electrode cell.

TABLE $4 \mid \mathrm{P}$ and $\mathrm{E}$ obtained for the capacitors at a potential window of $1.6 \mathrm{~V}$ in $0.5 \mathrm{M} \mathrm{H}_{2} \mathrm{SO}_{4}$ as electrolyte.

\begin{tabular}{|c|c|c|c|c|c|}
\hline Device & $\frac{P_{\max }}{\left(\mathbf{k W ~}^{-1} \mathbf{g}^{-1}\right)}$ & $\begin{array}{c}P_{\max } \\
\left(k W d^{-3}\right)\end{array}$ & $\begin{array}{c}E \\
\left(W k^{-1}\right)\end{array}$ & $\begin{array}{c}E \\
\left(W \mathrm{dm}^{-3}\right)\end{array}$ & $\begin{array}{c}E_{\text {calc }} \\
\left(W \mathrm{~h} \mathrm{~kg}^{-1}\right)\end{array}$ \\
\hline$A C \| A C$ & 0.5 & 0.1 & 15.3 & 2.2 & 26.7 \\
\hline $\mathrm{AC} \| \mathrm{ACF}$ & 1.7 & 0.3 & 18.1 & 2.7 & 18.2 \\
\hline $\begin{array}{l}\text { AC\|ACF/ } \\
\text { PANI }\end{array}$ & 2.1 & 0.6 & 20.0 & 5.7 & 21.4 \\
\hline
\end{tabular}

Table 4 includes the energy density values for the unpackagedactive material and power density (gravimetric and volumetric basis) as well as the theoretical energy density values using the method described elsewhere (Snook et al., 2009). These theoretical energy density values are close to those obtained experimentally for the asymmetric capacitors, which validates the correct design of the asymmetric EC.

Both power and energy density values increase more than $20 \%$ in presence of PANI. The energy and power density values obtained for asymmetric AC||ACF/PANI supercapacitor were close to those obtained in organic electrolyte for supercapacitors based on AC\|graphitic carbon (18 W h kg-1 and $6.4 \mathrm{~kW} \mathrm{~kg}^{-1}$ ) and higher than those obtained in aqueous electrolyte (Simon and Burke, 2008). In addition, the AC\|ACF/PANI performance was higher than other previous systems based on PANI or PANI/CM composite (Fusalba et al., 2001; Park and Park, 2002; Meng et al., 2010; Wu et al., 2010), although this comparison is difficult and it could be slightly inaccurate.

On the basis of the results obtained, PANI thin film inside the microporosity of ACF plays a key role in the improvement in power and energy density values of the asymmetric supercapacitors because of redox processes increased the capacitance of the positive electrode. Additionally, PANI film reduced the oxidation of ACF and increased its cycle life, which in turn enhanced the AC $\| \mathrm{ACF} / \mathrm{PANI}$ supercapacitor. This can be considered as an interesting strategy to get advantage of both the high porosity of the porous carbons and the pseudocapacitance of the CP.

\section{EC Using Lignin-Based Porous Carbons: An Environmentally Friendly Approach}

This section presents an example of assembling an asymmetric supercapacitor in mass using porous carbons that have been derived from a biomass residue. These porous carbons can be used to design sustainable and inexpensive electrode material. The carbon material selected in this study was lignin-based hierarchical porous carbons (HPCs) synthesized by carbonization of lignin-zeolite mixtures (Valero-Romero et al., 2014). The use of these lignin-based HPCs described by ValeroRomero et al. (2014) was motivated by the environmentally friendly synthesis method, since lignin is one on the most abundant biopolymer in Earth and the use of a zeolite as template to generate porosity allows to avoid chemical activation with corrosive agents. A previous study of these lignin-based HPCs showed an outstanding electrochemical behavior in acidic medium (Ruiz-Rosas et al., 2014). Thus, some of these ligninbased HPCs attained $250 \mathrm{~F} \mathrm{~g}^{-1}$ (three-electrode cell) and showed a relevant capacitance retention at high current densities due to their interconnected porous network.

The preparation of lignin-based HPCs consisted of mixing a lignin solution in ethanol with zeolite $\mathrm{Y}$ or BETA according to Valero-Romero et al procedure (Valero-Romero et al., 2014). Samples were named as L-Y-900 and L-B-900 according to the template and temperature used. Their $\mathrm{C}, \mathrm{O}$, and $\mathrm{N}$ mass surface concentrations were around $84-86,12-15$, and $1-2 \%$, respectively. From Figure 6A, it can be observed that the zeolite structure influenced the final porosity. L-Y-900 showed high gas uptake at low relative pressures (micropores) and a small hysteresis loop at a relative pressure of 0.4 (small mesopore volume), while L-B-900 also displayed a high $\mathrm{N}_{2}$ uptake at low pressures, but its hysteresis loop was larger than L-Y-900 and shifted at relative pressures of 0.7-0.9 (large mesopore volume). For comparison purposes, a commercial activated carbon (ACR) 

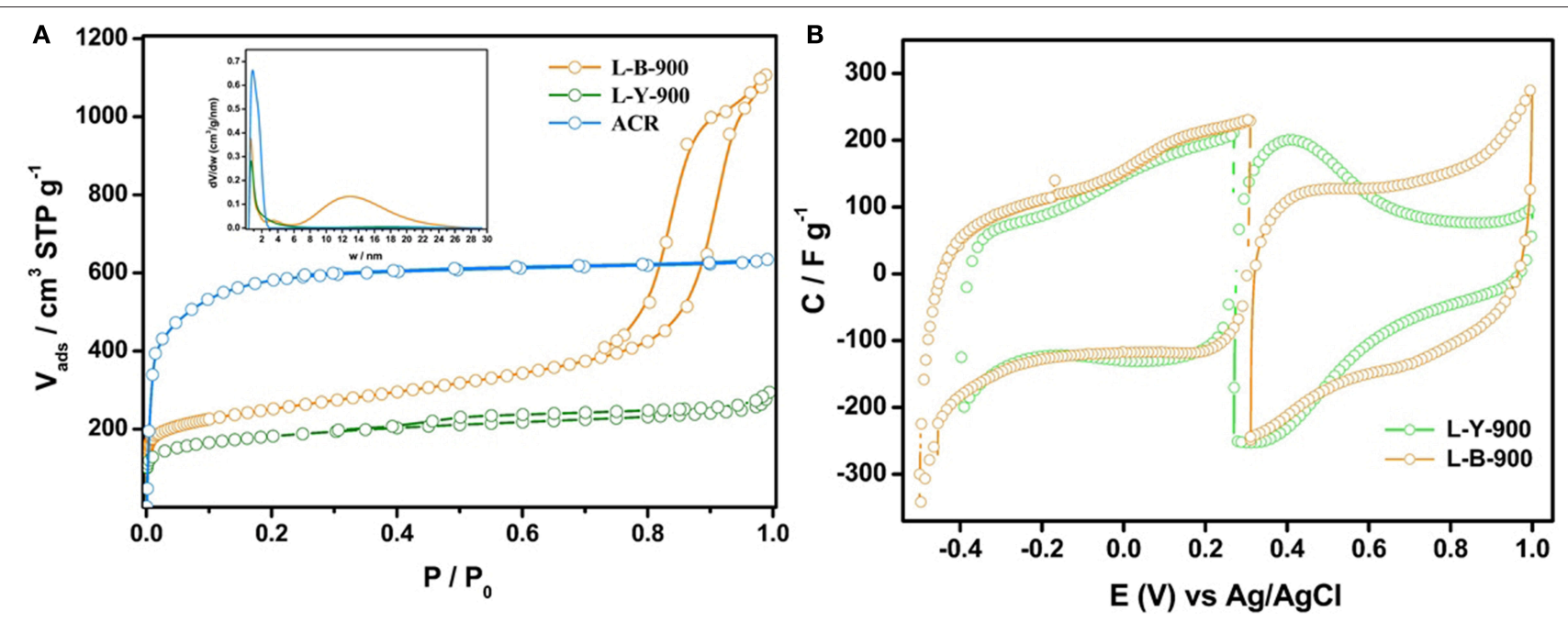

FIGURE 6 | (A) N2 adsorption-desorption isotherms for all samples (The inset depicts their PSD). (B) Steady voltammograms from for both lignin-based HPCs.

was used (mainly microporous). The pore size distribution (inset of Figure 6A) confirmed that both lignin-based HPCs possessed a similar volume of micropores and average micropore size. The mesoporosity of L-Y-900 ranged from 2 to $6 \mathrm{~nm}$, while L-B900 presented a larger size distribution $(7-24 \mathrm{~nm})$, which was in agreement with the pore size obtained from TEM images.

Both L-B-900 and L-Y-900 were studied in a three-electrode cell to assess the stability potential window. It must be noted that L-Y-900 has reactive edges sites in its structure, which are susceptible of being electrooxidized (Ruiz-Rosas et al., 2014). Hence, L-Y-900 was previously electrooxidized by $\mathrm{CV}$ before building the supercapacitor to stabilize its electrochemical behavior. Figure 6B shows the voltammograms from $E_{O C P}$ to the upper and lower potential limits for both samples, which were carefully chosen for the design of the asymmetric supercapacitor.

On the one hand, the voltammogram to negative potential values for L-Y-900 showed a quasi-rectangular shape with some pseudocapacitance contribution close to $\mathrm{E}_{\mathrm{OCP}}$, which was assigned to redox processes of CO-evolving oxygen groups (Bleda-Martínez et al., 2005), and a small current at $-0.4 \mathrm{~V}$ related to the reduction of carbon material (Cheng and Teng, 2003) or the hydrogen evolution reaction (Bleda-Martínez et al., $2008 \mathrm{~b}$ ). On the other hand, the voltammogram of L-Y-900 recorded to positive potentials displayed a broad peak $(0.4 \mathrm{~V})$, which was related to the high concentration of electroactive COevolving surface oxygen groups (see Table 5) (Bleda-Martínez et al., 2005). Moreover, the voltammogram shape was similar to those obtained in acid electrolyte for other templated porous carbons using the zeolite Y (Ania et al., 2007; Itoi et al., 2014). The voltammograms of L-B-900 sample recorded from $\mathrm{E}_{\mathrm{OCP}}$ to the upper and the lower potential limits showed a lower pseudocapacitance contribution than L-Y-900, which was in agreement with the lower amount of CO-type groups in L-B900 (see Table 5). From GCD curves, specific capacitance values for each lignin-based HPCs electrode was accurately determined and according to their relatively low ohmic drop for both L-Y-900 and L-B-900 at $2 \mathrm{~A} \mathrm{~g}^{-1}$, it was concluded that these lignin-based HPCs possessed an important connectivity between pores because the ion diffusion was not hampered.

After that, asymmetric supercapacitors based on both L-B-900 and L-Y-900 were built following the procedure shown in section AC/AC-Based Asymmetric EC: Opening the Operating EC Voltage. Moreover, the symmetric counterparts were also assembled as well as a commercial activated carbon-based symmetric supercapacitor (named ACR).

After assembling all symmetric supercapacitors, chargedischarge experiments at different current densities were performed to stabilize the electrochemical behavior. It was observed that the cell resistance was lower in the case of ligninbased HPCs than ACR. It could be indicative of better electrical conductivity and charge transfer, which might be assigned to the specific properties of lignin to produce highly conductive microporous carbon materials (Berenguer et al., 2016). The effect of the lower resistance on the performance was observed in the Ragone plot (Figure 7). ACR-based supercapacitor delivered an energy density of $9.9 \mathrm{~W} \mathrm{~h} \mathrm{~kg}^{-1}$ at $0.53 \mathrm{~kW} \mathrm{~kg}^{-1}$, while both L-B-900 and L-Y-900 supercapacitors supplied 4.8 and $2.9 \mathrm{~W} \mathrm{~h} \mathrm{~kg}^{-1}$, respectively. However, this meaningful difference dropped when higher power output was demanded and the better performance in terms of energy density was presented by HPCs due to their capacitance retention. As the current density was increased from 1 to $64 \mathrm{~A} \mathrm{~g}^{-1}$, both L-Y-900 and L-B-900 retained 48 and $44 \%$ of the initial value, respectively, while the supercapacitor based on ACR lost $77 \%$ of the initial capacitance value. This points out the advantages of the interconnected porosity of these HPCs, delivering higher energy density than ACR devices for short discharge times.

Taking into account this maximum voltage for both L-B$900(1.5 \mathrm{~V})$ and L-Y-900 $(1.4 \mathrm{~V})$ as well as the capacitance 
TABLE 5 | Porous texture and surface chemistry characterization of all samples.

\begin{tabular}{|c|c|c|c|c|c|}
\hline Sample & $\mathrm{SSA} / \mathrm{m}^{2} \mathrm{~g}^{-1}$ & $V_{D R} N_{2} / \mathrm{cm}^{3} \mathrm{~g}^{-1}$ & $\mathrm{~V}_{\mathrm{meso}} / \mathrm{cm}^{3} \mathrm{~g}^{-1}$ & $\mathrm{CO} / \mu \mathrm{mol} \mathrm{g}-1$ & $\mathrm{CO}_{2} / \mu \mathrm{mol} \mathrm{g}-1$ \\
\hline L-Y-900 & 670 & 0.27 & 0.10 & 1,310 & 470 \\
\hline L-B-900 & 930 & 0.36 & 1.19 & 800 & 90 \\
\hline ACR & 2,180 & 0.93 & 0.06 & 1,440 & 380 \\
\hline
\end{tabular}

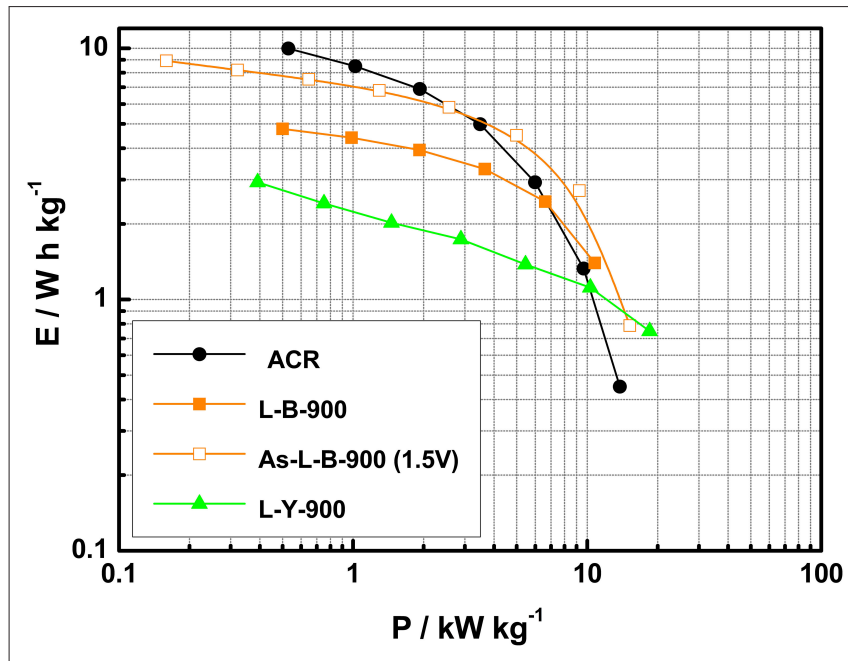

FIGURE 7 | Ragone plot for the symmetric supercapacitors (L-B-900, $\mathrm{L}-\mathrm{Y}-900, \mathrm{ACR}$, solid dots) at a cell voltage of $1.2 \mathrm{~V}$ and the asymmetric based on L-B-900 (hollow dots).

determined by charge-discharge experiments, the mass ratio was optimized to build asymmetric supercapacitors following the method described in section AC/AC-Based Asymmetric EC: Opening the Operating EC Voltage (Peng et al., 2010; Chae and Chen, 2012). The resulting devices demonstrated both a good stability and an improvement in gravimetric capacitance. Figure 7 shows as an example the Ragone plot for the asymmetric capacitor built with samples L-B-900 working up to $1.5 \mathrm{~V}$. The As-L-B-900 supercapacitor was compared to its symmetric counterpart and the ACR-based symmetric supercapacitor. Even though a higher energy density was delivered by ACR at fixed power density (1.3 kW kg-1), a much better energy efficiency was given by the L-B-900 supercapacitors. Moreover, the energy density increased by 35 and $44 \%$ at 1.4 and $1.5 \mathrm{~V}$, respectively, when the asymmetric configuration was used.

Asymmetric L-B-900 improved the energy density delivered, while keeping the high power that is characteristic of using HPCs as electrode materials (see Figure 7). The As-L-B-900 working at $1.5 \mathrm{~V}$ showed better energy density than ACR from a power density of $3.1 \mathrm{~kW} \mathrm{~kg}^{-1}$, which was a promising result according to the much lower SSA displayed by L-B-900. Finally, durability tests were performed by charge-discharge at $1 \mathrm{~A} \mathrm{~g}^{-1}$ for 5,000 cycles and it was observed that As-L-B-900 (1.5 V) suffered a noticeable drop in its performance. Given that As-L-B-900 $(1.4 \mathrm{~V})$ showed an energy density similar to that obtained at $1.5 \mathrm{~V}$, it was concluded that the most adequate voltage to improve both energy density and stability for As-L-B-900 supercapacitor was $1.4 \mathrm{~V}$. Therefore, this example demonstrates that the massbalancing of electrodes and the sustainable approach used for the preparation of these electrodes can lead to the production of greener supercapacitors with improved performance.

\section{PERSPECTIVE AND POSSIBLE RESEARCH DIRECTIONS FOR OVERCOMING THE CHALLENGES FOR SPREADING THE USE OF CARBON NANOMATERIALS IN ELECTROCHEMICAL CAPACITORS}

In the previous sections, we have illustrated the huge advantages in electrochemical capacitor performance that can be achieved by using carbon nanomaterials as electrodes. However, some important challenges are still to be addressed for widespread utilization of these materials. The most important factor that needs to be improved is the cost. Nowadays, most of the electrode material employed in conventional supercapacitors consists of activated carbon prepared from biomass wastes. The use of lowcost carbon materials is one of the reasons behind the large drop in the price of supercapacitors, which fell below 0.01 \$ per farad in 2010 (Conte, 2010). The production cost of such activated carbons is much lower than engineered carbon nanomaterials, and the improvement in the performance cannot compensate such a huge difference.

Chen et al. (2009) in a critical review endorsed the use of supercapacitors for high power and power quality applications and labeled the technical maturity of electrochemical capacitors as developed, but they are also cataloged as expensive devices in terms of the stored energy capacity. Recently, Miller evaluated the current commercial applications of supercapacitors and identified the cost per $\mathrm{kWh}$ of a supercapacitor to be roughly 20 times higher than that of Li-ion batteries, and even when considering the power requirement, similar implementation costs for both devices are obtained for these niches applications. Only the long life cycle, reduced volume for equivalent power requirement and safer operation of supercapacitors can explain their ability to replace batteries in these applications (Miller, 2016). At this point, even though nanostructured carbons are the best choice in high power stationary and mobile applications because of their unmatched electrical conductivity and improved ion mobility, their cost could not be assumable unless they are produced using less expensive methods. Nishihara and Kyotani's review on templated nanocarbons concludes with an explicit mention about the high production cost and poor massproductivity (Nishihara and Kyotani, 2012). They claim that 


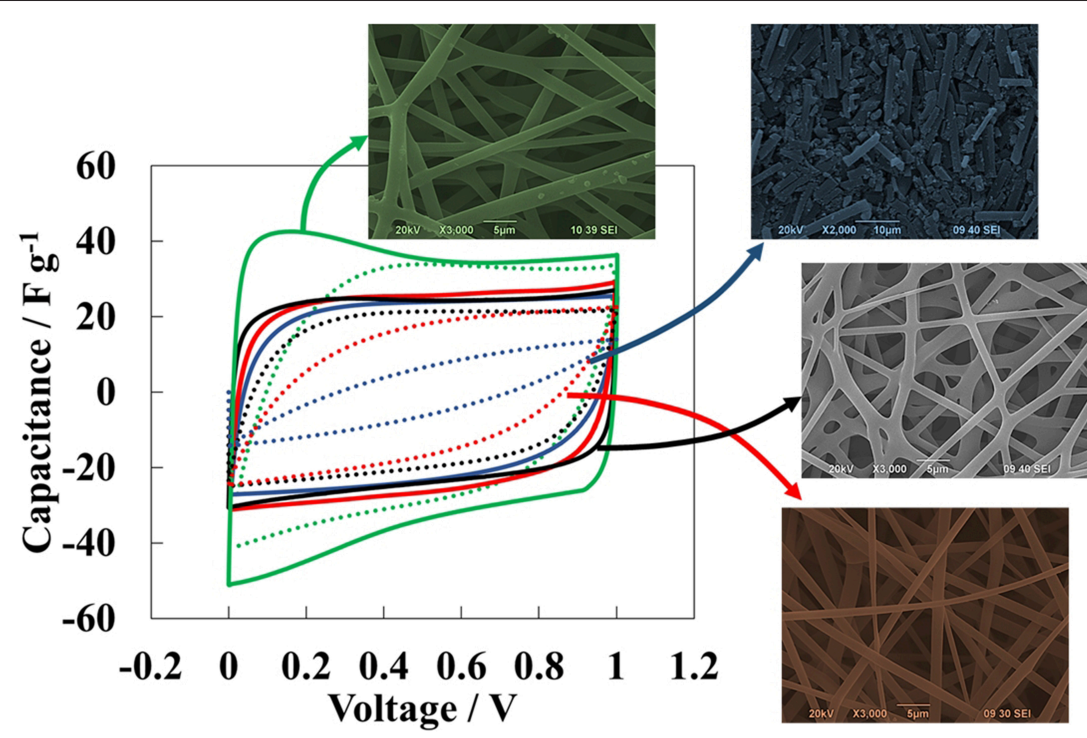

FIGURE 8 | Cyclic voltammetry at 0.1 (solid lines) and $1.0 \mathrm{~V} \mathrm{~s}^{-1}$ (dashed lines) of 2-electrode supercapacitor cells using milled carbon papers electrodes prepared using PTFE as binder and a carbon black as conductivity promoter (blue lines); self-standing carbon paper electrodes (red lines); self-standing and interconnected carbon paper electrodes (black lines); self-standing and interconnected carbon paper electrodes carbonized in 1\% air (green lines).

the performance of the templated nanocarbons are actually not superior enough to that of conventional highly porous activated carbons, so that the production cost gap between them cannot be compensated. Salunkhe et al. (2014) also concluded that the production cost is one of the future challenges of nanoarchitectured carbons-based supercapacitors.

Another important issue to reduce the production cost is the processing of the electrodes and cell assembly and match the application requirements. Handling and shaping of nanostructured carbon materials into electrodes are difficult tasks, and novel techniques are currently being developed for facilitate those processes. Also, the development of portable and wearable electronics, and the miniaturization of such devices have experimented a large boost in the last years, and they constitute a niche application where carbon nanomaterials can be the answer for the technical challenges brought by these devices.

As was mentioned, the use of wastes and biomass as precursors is one of the most promising trends for reducing costs of carbon nanomaterials. Dutta et al. (2014) recently reviewed on the production of hierarchical nanostructured carbons from biomass and biopolymers that have an excellent mass transfer and ion mobility, where mesopores act as ion reservoirs and provide high accessibility to micropores, which are responsible for boosting the capacitance of the electrode. This review encompasses the preparation techniques of such carbons (hard-templating or nanocasting, soft-templating, and non-templating routes). Ravi and Vadukumpully (2015) published a review about the use of biomass wastes and other low-cost precursors in the production of CNTs, graphene, quantum dots and so on.

We have recently reported the electrochemical performance of hierarchical porous carbon produced from lignin as carbon source (Ruiz-Rosas et al., 2014). Lignin is one of the most abundant biopolymers in nature and its high availability, reduced cost and a relatively high carbon and aromatic content, make it a suitable precursor for the production of nanostructured carbon materials (Rosas et al., 2014). In this work, the resulting HPCs exhibited interesting electrochemical features such as a high capacitance and an outstanding capacitance retention. The aforementioned results highlight the possibility of "greening" the production of nanostructured porous carbons by choosing inexpensive biomass byproducts as precursors (Ruiz-Rosas et al., 2014; Quesada-Plata et al., 2016).

It is worthy of mention the concept of microcapacitor that arises for fulfilling the requirements of electronic self-powered devices. The use of nanostructured carbon materials in microcapacitors solves the main drawback of the first microcapacitors based on CPs with short cycle life.

Ink printing is one of the most effective techniques for fabricating thin film electrodes from nanostructured carbon. Lawes et al. (2015) reviewed the preparation of energy storage devices using inkjet printing that makes possible to cast electrode materials on large-area flexible substrates. Moreover, through patterning and printing several different layers, the topology of the electrodes could be controlled, allowing the combination of materials for tuning the performance of the supercapacitors. The aforementioned review provides an example about the printing of activated carbon electrodes (Pech et al., 2010), but it is also claimed that in most cases, carbon nanomaterials like CNTs (Kordás et al., 2006) and graphene (Le et al., 2011) are preferred for this technique to achieve controllable thickness lower than $25 \mu \mathrm{m}$ (Lawes et al., 2015). Other suitable techniques for the production of microcapacitors are selective etching of 
TABLE 6 | Summary of NCMs used as electrodes in flexible EC.

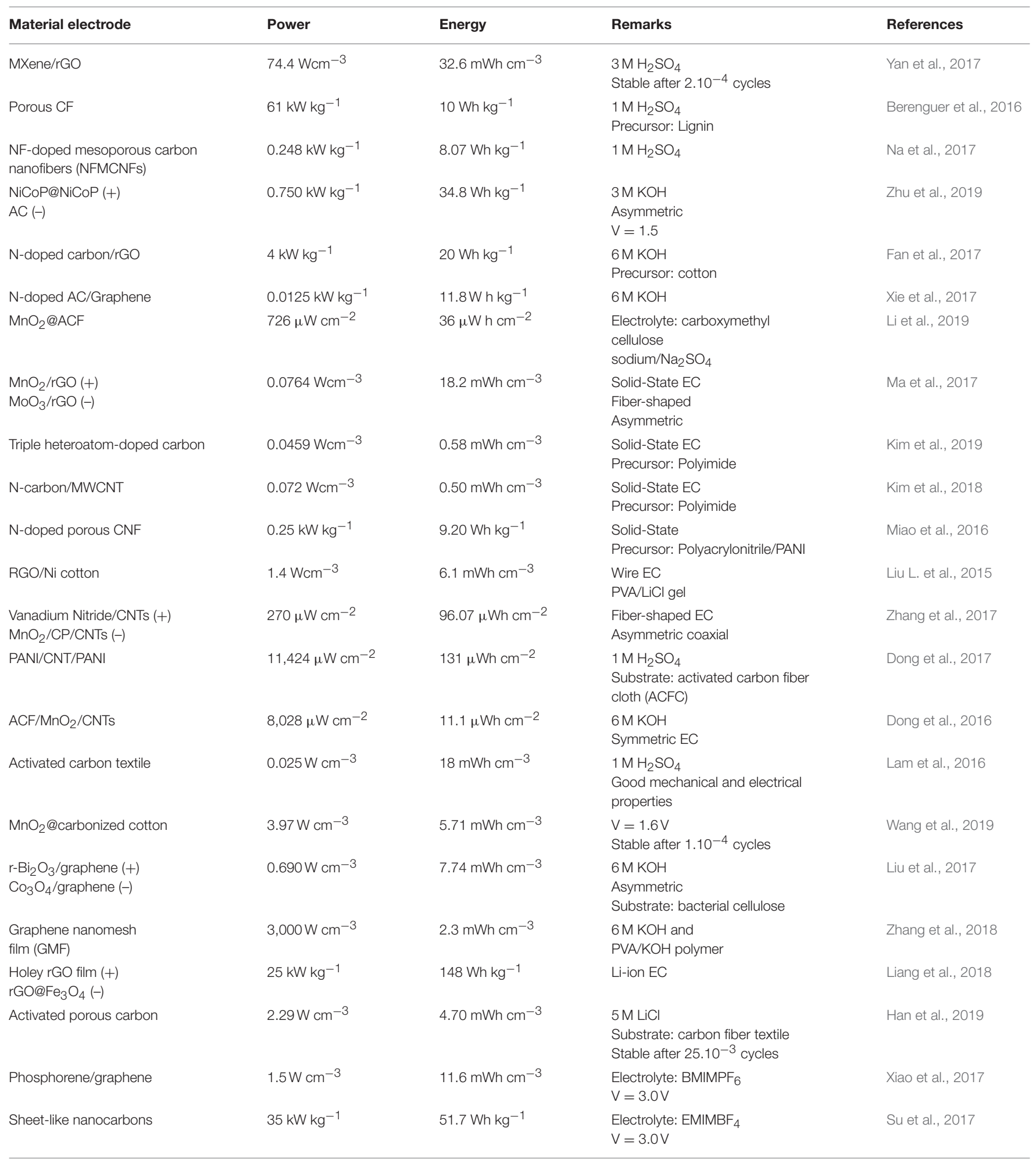

titanium carbide substrates (Chmiola et al., 2010), chemical vapor deposition (CVD), laser-induced porous graphene (Gao et al., 2011; Lin et al., 2014) and electrospray of CNT or graphene suspensions (Kim et al., 2006; Tang et al., 2015).
In the case of hard templated carbons, electrophoretic deposition of the template followed by the preparation of the carbon material is an interesting alternative for the production of thin films (Berenguer-Murcia et al., 2013). The capacitance 
retention of the powdered sample at high scan rates was lower than that of the ZTC thin film deposited on the carbon collector. Leyva-García et al. (2016a) prepared a binderless thin film made of mesoporous carbon material using a mesoporous silica thin film as hard-template. This process produced a continuous mesoporous carbon thin film having a mean pore size between 2 and $3 \mathrm{~nm}$. The 2-electrode microcapacitor cell based on the amorphous carbon and the composite thin film achieved capacitance values of 5.0 and $3.7 \mathrm{mF} \mathrm{cm}{ }^{-2}$ at $5 \mathrm{~mA} \mathrm{~cm}$, respectively. Moreover, full capacitance retention remained after 50,000 cycles. It indicates that electrophoretic deposition or dipcoating of hard templates are promising strategies to prepare binderless thin film of nanostructured carbon materials with outstanding performances.

Kyotani et al. (1997) and Itoi et al. (2011) reported a different approach by preparing a highly microporous ZTC with $\left(\mathrm{S}_{\mathrm{BET}} \sim 3,600 \mathrm{~m}^{2} \mathrm{~g}^{-1}\right)$ and a three-dimensional ordered structure consisting of a highly curved graphene layer. It showed improved ion mobility and proneness to be easily electro-oxidized, forming $\mathrm{CO}$-evolving oxygen groups that boosted the pseudocapacitance in acid electrolyte (Nueangnoraj et al., 2014). However, the preparation of a thin film from the powdered form or the replication of this structure is a challenge. The use of electrospray to prepare thin films of superporous ZTC on different substrates with adjustable thicknesses has already been proposed to overcome these hurdles (Rosas et al., 2016).

Among the alternatives encompassed toward the fabrication of supercapacitors, the use of flexible EC is expected to be an outstanding option able to fulfill the requirement to be utilized in countless valuable applications in portable and wearable electronic devices (Chen et al., 2017; Muzaffar et al., 2019). In these systems, the electrode material is usually composed by either a thin film of nanostructured materials or by a binderless, flexible textile electrode (Ye et al., 2018). The electrodes of these devices should be highly conductive and have a large energy density in addition to good mechanical properties.

In this sense, graphene was identified as a unique material for this purpose because of its atom-thick two-dimensional structure (Zhong et al., 2015), what makes graphene sheets easily bendable in the direction normal to its surface, providing it with good flexibility (Wang and Shi, 2015). However, CNTs, CNTs/graphene or carbon microfiber are also an excellent alternative as active phase in these devices (Cheng et al., 2013; Park et al., 2013) as self-standing electrodes in flexible supercapacitors (Zhang et al., 2015).

The two main strategies for their production are (Nyholm et al., 2011; Dubal et al., 2014; Ginting et al., 2018; Heo et al., 2018): (i) to support the active materials (metal oxides or CPs) on flexible substrates (metal sheet, carbon paper or insulating support) from dipping-dry to electrodeposition (Hu et al., 2010; Tang et al., 2015), CVD, electrografting (Aqil et al., 2015), etc. (ii) the fabrication of flexible free-standing films of the active materials (mainly nanostructured carbon materials that act as both the active phase and the current collector). These flexible free-standing films can be attained from fibrillar forms of carbon, such as CNTs, carbon nanofibers and activated carbon microfibers (Shi et al., 2013). Free-standing CNT films can be prepared by methods such as filtration and evaporation, and can be easily transferred to the plastic substrate to pack them into cells.

One of the most suitable methods for the production of freestanding electrodes is electrospinning. Berenguer et al. (2016) recently reported the outstanding performance of seamless carbon electrodes prepared by the electrospinning of lignin solution followed by their air stabilization and carbonization. Carbon fibers of $1 \mu \mathrm{m}$ in diameter, high structural order and surface areas as high as $1,100 \mathrm{~m}^{2} \mathrm{~g}^{-1}$ can be obtained using this method (Lallave et al., 2007). Interestingly, as the heating rate of the stabilization step was increased over the allowable limit, partial melting of the lignin fibers was observed. This resulted in an improved electrical conductivity of the resulting film.

Thus, supercapacitors based on these self-standing paper electrodes made of carbonized electrospun lignin fibers were assessed. Additionally, a supercapacitor based on these selfstanding paper was processed using a conventional procedure for what the carbon paper was milled along with a conductivity promoter and a binder. The destruction of such morphology revealed that the fiber morphology is responsible for the remarkable capacitance retention (see Figure 8) (Berenguer et al., 2016). Moreover, the interconnection of fibers achieved by partial melting of lignin delivered an improvement in the capacitance retention (solid black voltammogram, Figure 8).These results point out that self-standing, flexible electrodes with outstanding performance are achievable using green precursors and alternative techniques as electrospinning.

Some of the most representative breakthroughs achieved in the field of flexible capacitors based on carbon materials are summarized in Table 6.

As a summary, supercapacitors are considered as a mature technology. However, their performance needs to be improved in order to expand their potential applications, whereas their costs per Farad and Watt-hour still need to be lowered. In this sense, the use of nanostructured carbon materials could be highly beneficial. Although many challenges are still ahead, expectations are high, and the next years would probably bring a huge development in the commercial implementation of these materials as electrodes of novel forms of supercapacitors.

\section{CONCLUSIONS}

Herein we review the recent breakthroughs achieved in the field of supercapacitors. Most researches on EC have been addressed to enhance the energy output by designing the electrode materials, many other issues have been also tackled. In this vein, the search of new electrolytes and the optimization of advanced configurations have been studied. Regarding the electrode materials, $\mathrm{N}$-doped carbon materials have been attracted the attention because the introduction of nitrogen functionalities into the carbon network enhances important properties, such as electrical conductivity, wettability, and the 
stability of the material. As for the electrolytes, ionic liquids are being lately studied due to its large electrochemical stability voltage, while aqueous electrolytes have also caught the attention because of the higher capacitance of the electrode materials in this medium in comparison to organic electrolytes. However, the low potential stability window of aqueous electrolytes have motivated the study of new configurations (hybrid and asymmetric) in order to expand the voltage of the devices. In the view of the recent advances in the field of ECs, it can be envisaged that the future direction will be focused on the development of lightweight and flexible electrode materials. At this point, graphene and CNTs are the main alternatives, however, the main shortcoming to reach the target application is the large scale production of ECs based on these carbon materials because of their high cost to produce them. In conclusion, the development of energy-storage devices should consider the performance of the resulting EC as well as the production costs in order to implement these devices in practical applications such as portable electronics or hybrid electric vehicles.

\section{REFERENCES}

Ania, C. O., Khomenko, V., Raymundo-Piñero, E., Parra, J. B., and Béguin, F. (2007). The large electrochemical capacitance of microporous doped carbon obtained by using a zeolite template. Adv. Funct. Mater. 17, 1828-1836. doi: 10.1002/adfm.200600961

Aqil, A., Vlad, A., Piedboeuf, M.-L., Aqil, M., Job, N., Melinte, S., et al. (2015). A new design of organic radical batteries (ORBs): carbon nanotube buckypaper electrode functionalized by electrografting. Chem. Commun. 51, 9301-9304. doi: $10.1039 / \mathrm{c} 5 \mathrm{cc} 02420 \mathrm{j}$

Arcila-Velez, M. R., Zhu, J., Childress, A., Karakaya, M., Podila, R., Rao, A. M., et al. (2014). Roll-to-roll synthesis of vertically aligned carbon nanotube electrodes for electrical double layer capacitors. Nano Energy 8, 9-16. doi: 10.1016/j.nanoen.2014.05.004

Augustyn, V., Simon, P., and Dunn, B. (2014). Pseudocapacitive oxide materials for high-rate electrochemical energy storage. Energy Environ. Sci. 7:1597. doi: $10.1039 / \mathrm{c} 3 \mathrm{ee} 44164 \mathrm{~d}$

Balducci, A. (2016). Electrolytes for high voltage electrochemical double layer capacitors: a perspective article. J. Power Sources 326, 534-540. doi: 10.1016/j.jpowsour.2016.05.029

Berenguer, R., García-Mateos, F. J., Ruiz-Rosas, R., Cazorla-Amorós, D., Morallón, E., Rodríguez-Mirasol, J., et al. (2016). Biomass-derived binderless fibrous carbon electrodes for ultrafast energy storage. Green Chem. 18, 1506-1515. doi: 10.1039/C5GC02409A

Berenguer-Murcia, Á., Ruiz-Rosas, R. R., García-Aguilar, J., Nueangnoraj, K., Nishihara, H., Morallón, E., et al. (2013). Binderless thin films of zeolitetemplated carbon electrodes useful for electrochemical microcapacitors with ultrahigh rate performance. Phys. Chem. Chem. Phys. 15, 10331-10334. doi: $10.1039 / \mathrm{C} 3 \mathrm{CP} 51945 \mathrm{G}$

Bichat, M. P., Raymundo-Piñero, E., and Béguin, F. (2010). High voltage supercapacitor built with seaweed carbons in neutral aqueous electrolyte. Carbon 48, 4351-4361. doi: 10.1016/j.carbon.2010.07.049

Bleda-Martínez, M. J., Lozano-Castelló, D., Cazorla-Amorós, D., and Morallón, E. (2010). Kinetics of double-layer formation: influence of porous structure and pore size distribution. Energy and Fuels 24, 3378-3384. doi: 10.1021/ef901521g

Bleda-Martínez, M. J., Lozano-Castelló, D., Morallón, E., Cazorla-Amorós, D., and Linares-Solano, A. (2006). Chemical and electrochemical characterization of porous carbon materials. Carbon 44, 2642-2651. doi: 10.1016/j.carbon.2006.04.017

\section{AUTHOR CONTRIBUTIONS}

DS-T performed and analyzed the experiments related to the publications summarized in the present review. DS-T conceived and wrote this manuscript. RR-R contributed to the manuscript writing and revision. EM and DC-A contributed to the design and conception of the study and discussion of the results as well as the manuscript writing and revision. All authors approved the manuscript for publication.

\section{FUNDING}

We want to acknowledge the financial support by the Ministry of Economy and Competitiveness of Spain (MINECO) and FEDER (CTQ2015-66080-R MINECO/FEDER and MAT2016-76595-R).

\section{ACKNOWLEDGMENTS}

DS-T (J171015004) thanks JSPS for the International Postdoctoral Research Fellowships.

Bleda-Martínez, M. J., Maciá-Agulló, J. A., Lozano-Castelló, D., Morallón, E., Cazorla-Amorós, D., and Linares-Solano, A. (2005). Role of surface chemistry on electric double layer capacitance of carbon materials. Carbon 43, 2677-2684. doi: 10.1016/j.carbon.2005.05.027

Bleda-Martínez, M. J., Peng, C., Zhang, S., Chen, G. Z., Morallón, E., and CazorlaAmorós, D. (2008a). Electrochemical methods to enhance the capacitance in activated carbon/polyaniline composites. J. Electrochem. Soc. 155, A672-A678. doi: $10.1149 / 1.2956969$

Bleda-Martínez, M. J., Pérez, J. M., Linares-Solano, A., Morallón, E., and Cazorla-Amorós, D. (2008b). Effect of surface chemistry on electrochemical storage of hydrogen in porous carbon materials. Carbon 46, 1053-1059. doi: 10.1016/j.carbon.2008.03.016

Boehm, H. (2002). Surface oxides on carbon and their analysis: a critical assessment. Carbon 40, 145-149. doi: 10.1016/S0008-6223(01)00165-8

Bose, S., Kuila, T., Mishra, A. K., Rajasekar, R., Kim, N. H., and Lee, J. H. (2012). Carbon-based nanostructured materials and their composites as supercapacitor electrodes. J. Mater. Chem. 22, 767-784. doi: 10.1039/C1JM14468E

Brousse, T., Belanger, D., and Long, J. W. (2015). To be or not to be pseudocapacitive? J. Electrochem. Soc. 162, A5185-A5189. doi: 10.1149/2.0201505jes

Candelaria, S. L., Garcia, B. B., Liu, D., and Cao, G. (2012). Nitrogen modification of highly porous carbon for improved supercapacitor performance. J. Mater. Chem. 22:9884. doi: 10.1039/C2JM30923H

Cazorla-Amorós, D., Lozano-Castelló, D., Morallón, E., Bleda-Martínez, M. J., Linares-Solano, A., and Shiraishi, S. (2010). Measuring cycle efficiency and capacitance of chemically activated carbons in propylene carbonate. Carbon 48 , 1451-1456. doi: 10.1016/j.carbon.2009.12.039

Chae, J. H., and Chen, G. Z. (2012). 1.9V aqueous carbon-carbon supercapacitors with unequal electrode capacitances. Electrochim. Acta 86, 248-254. doi: 10.1016/j.electacta.2012.07.033

Chen, C., Fan, W., Zhang, Q., Fu, X., and Wu, H. (2015). One-step hydrothermal synthesis of nitrogen and sulfur co-doped graphene for supercapacitors with high electrochemical capacitance performance. Ionics 21, 3233-3238. doi: 10.1007/s11581-015-1522-z

Chen, H., Cong, T. N., Yang, W., Tan, C., Li, Y., and Ding, Y. (2009). Progress in electrical energy storage system: a critical review. Prog. Nat. Sci. 19, 291-312. doi: 10.1016/j.pnsc.2008.07.014

Chen, X., Paul, R., and Dai, L. (2017). Carbon-based supercapacitors for efficient energy storage. Natl. Sci. Rev. 4, 453-489. doi: 10.1093/nsr/nwx009 
Chen, Y., Zhang, J., Li, M., Yang, C., Zhang, L., Wang, C., et al. (2018). Strong interface coupling and few-crystalline $\mathrm{MnO}_{2} /$ Reduced graphene oxide composites for supercapacitors with high cycle stability. Electrochim. Acta 292, 115-124. doi: 10.1016/j.electacta.2018.09.131

Chen, Y. M., Li, Z., and Lou, X. W. (2015). General formation of $\mathrm{M}_{\mathrm{X}} \mathrm{Co}_{3-\mathrm{X}} \mathrm{S}_{4}$ $(\mathrm{M}=\mathrm{Ni}, \mathrm{Mn}, \mathrm{Zn})$ hollow tubular structures for hybrid supercapacitors. Angew. Chem. Int. Ed. 54, 10521-10524. doi: 10.1002/anie.201504349

Chen, Z., Augustyn, V., Wen, J., Zhang, Y., Shen, M., Dunn, B., et al. (2011). High-performance supercapacitors based on intertwined CNT/ $\mathrm{V}_{2} \mathrm{O}_{5}$ nanowire nanocomposites. Adv. Mater. 23, 791-795. doi: 10.1002/adma.201003658

Cheng, H., Dong, Z., Hu, C., Zhao, Y., Hu, Y., Qu, L., et al. (2013). Textile electrodes woven by carbon nanotube-graphene hybrid fibers for flexible electrochemical capacitors. Nanoscale 5, 3428-3434. doi: 10.1039/C3NR00320E

Cheng, P. Z., and Teng, H. (2003). Electrochemical responses from surface oxides present on HNO3-treated carbons. Carbon 41, 2057-2063. doi: 10.1016/S0008-6223(03)00212-4

Chmiola, J., Largeot, C., Taberna, P.-L., Simon, P., and Gogotsi, Y. (2010). Monolithic carbide-derived carbon films for micro-supercapacitors. Science 328, 480-483. doi: 10.1126/science. 1184126

Chmiola, J., Largeot, C., Taberna, P. L., Simon, P., and Gogotsi, Y. (2008). Desolvation of ions in subnanometer pores and its effect on capacitance and double-layer theory. Angew. Chemie Int. Ed. 47, 3392-3395. doi: 10.1002/anie.200704894

Chmiola, J., Yushin, G., Gogotsi, Y., Portet, C., Simon, P., and Taberna, P. L. (2006). Anomalous increase in carbon capacitance at pore sizes less than 1 nanometer. Science 313, 1760-1763. doi: 10.1126/science.1132195

Choudhury, N. A., Sampath, S., and Shukla, A. K. (2009). Hydrogel-polymer electrolytes for electrochemical capacitors: an overview. Energy Environ. Sci. 2, 55-67. doi: 10.1039/B811217G

Conte, M. (2010). Supercapacitors technical requirements for new applications. Fuel Cells 10, 806-818. doi: 10.1002/fuce.201000087

Conway, B. E. (1999). Electrochemical Supercapacitors. New York, NY: Plenum Publishers.

Conway, B. E., and Pell, W. G. (2003). Double-layer and pseudocapacitance types of electrochemical capacitors and their applications to the development of hybrid devices. J. Solid State Electrochem. 7, 637-644. doi: 10.1007/s10008-003-0395-7

Demarconnay, L., Raymundo-Piñero, E., and Béguin, F. (2010). A symmetric carbon/carbon supercapacitor operating at $1.6 \mathrm{v}$ by using a neutral aqueous solution. Electrochem. Commun. 12, 1275-1278. doi: 10.1016/j.elecom.2010.06.036

Demarconnay, L., Raymundo-Piñero, E., and Béguin, F. (2011). Adjustment of electrodes potential window in an asymmetric carbon $/ \mathrm{MnO}_{2}$ supercapacitor. J. Power Sources 196, 580-586. doi: 10.1016/j.jpowsour.2010.06.013

Deng, Y., Xie, Y., Zou, K., and Ji, X. (2015). Review on recent advances in nitrogendoped carbons: preparations and applications in supercapacitors. J. Mater. Chem. A 4, 1144-1173. doi: 10.1039/C5TA08620E

Deschamps, M., Gilbert, E., Azais, P., Raymundo-Piñero, E., Ammar, M. R., Simon, P., et al. (2013). Exploring electrolyte organization in supercapacitor electrodes with solid-state NMR. Nat. Mater. 12, 351-358. doi: 10.1038/nmat3567

Dong, L., Liang, G., Xu, C., Liu, W., Pan, Z.-Z., Zhou, E., et al. (2017). Multi hierarchical construction-induced superior capacitive performances of flexible electrodes for wearable energy storage. Nano Energy 34, 242-248. doi: 10.1016/j.nanoen.2017.02.031

Dong, L., Xu, C., Li, Y., Wu, C., Jiang, B., Yang, Q., et al. (2016). Simultaneous production of high-performance flexible textile electrodes and fiber electrodes for wearable energy storage. Adv. Mater. 28, 1675-1681. doi: 10.1002/adma.201504747

Du, J., Liu, L., Hu, Z., Yu, Y., Qin, Y., and Chen, A. (2018). Order mesoporous carbon spheres with precise tunable large pore size by encapsulated self-activation strategy. Adv. Funct. Mater. 28:1802332. doi: 10.1002/adfm.201802332

Dubal, D. P., Kim, J. G., Kim, Y., Holze, R., Lokhande, C. D., and Kim, W. B. (2014). Supercapacitors based on flexible substrates: an overview. Energy Technol. 2, 325-341. doi: 10.1002/ente.201300144

Dutta, S., Bhaumik, A., and Wu, K. C.-W. (2014). Hierarchically porous carbon derived from polymers and biomass: effect of interconnected pores on energy applications. Energy Environ. Sci. 7, 3574-3592. doi: 10.1039/C4EE01075B
Esconjauregui, S., Fouquet, M., Bayer, B. C., Ducati, C., Smajda, R., Hofmann, S., et al. (2010). Growth of ultrahigh density vertically aligned carbon nanotube forests for interconnects. ACS Nano 4, 7431-7436. doi: 10.1021/nn1025675

Falco, C., Marco-Lozar, J. P., Salinas-Torres, D., Morallón, E., CazorlaAmorós, D., Titirici, M. M., et al. (2013). Tailoring the porosity of chemically activated hydrothermal carbons: influence of the precursor and hydrothermal carbonization temperature. Carbon 62, 346-355. doi: 10.1016/j.carbon.2013.06.017

Fan, Y.-M., Song, W.-L., Li, X., and Fan, L.-Z. (2017). Assembly of graphene aerogels into the $3 \mathrm{D}$ biomass-derived carbon frameworks on conductive substrates for flexible supercapacitors. Carbon 111, 658-666. doi: 10.1016/j.carbon.2016.10.056

Fan, Z., Yan, J., Wei, T., Zhi, L., Ning, G., Li, T., et al. (2011). Asymmetric supercapacitors based on graphene/ $\mathrm{MnO}_{2}$ and activated carbon nanofiber electrodes with high power and energy density. Adv. Funct. Mater. 21, 2366-2375. doi: 10.1002/adfm.201100058

Faraji, S., and Ani, F. N. (2014). Microwave-assisted synthesis of metal oxide/hydroxide composite electrodes for high power supercapacitors-a review. J. Power Sources 263, 338-360. doi: 10.1016/ j.jpowsour.2014.03.144

Fei, H., Yang, C., Bao, H., and Wang, G. (2014). Flexible all-solid-state supercapacitors based on graphene/carbon black nanoparticle film electrodes and cross-linked poly(vinyl alcohol)- $\mathrm{H}_{2} \mathrm{SO}_{4}$ porous gel electrolytes. J. Power Sources 266, 488-495. doi: 10.1016/j.jpowsour.2014.05.059

Fic, K., Lota, G., Meller, M., and Frackowiak, E. (2012). Novel insight into neutral medium as electrolyte for high-voltage supercapacitors. Energy Environ. Sci. 5, 5842-5850. doi: 10.1039/C1EE02262H

Figueiredo, J. L., Pereira, M. F. R., Freitas, M. M. A., and Órfão, J. J. M. (1999). Modification of the surface chemistry of activated carbons. Carbon 37 , 1379-1389. doi: 10.1016/S0008-6223(98)00333-9

Forse, A. C., Merlet, C., Griffin, J. M., and Grey, C. P. (2016). New perspectives on the charging mechanisms of supercapacitors. J. Am. Chem. Soc. 138, 5731-5744. doi: 10.1021/jacs.6b02115

Frackowiak, E., Delpeux, S., Jurewicz, K., Szostak, K., CazorlaAmoros, D., and Béguin, F. (2002). Enhanced capacitance of carbon nanotubes through chemical activation. Chem. Phys. Lett. 361, 35-41. doi: 10.1016/S0009-2614(02)00684-X

Frackowiak, E., Khomenko, V., Jurewicz, K., Lota, K., and Béguin, F. (2006). Supercapacitors based on conducting polymers/nanotubes composites. J. Power Sources 153, 413-418. doi: 10.1016/j.jpowsour.2005.05.030

Frackowiak, E., Meller, M., Menzel, J., Gastol, D., and Fic, K. (2014). Redoxactive electrolyte for supercapacitor application. Faraday Discuss. 172, 179-198. doi: 10.1039/C4FD00052H

Frackowiak, E., Metenier, K., Bertagna, V., and Béguin, F. (2000). Supercapacitor electrodes from multiwalled carbon nanotubes. Appl. Phys. Lett. 77, 2421-2423. doi: $10.1063 / 1.1290146$

Fuertes, A. B., Pico, F., and Rojo, J. M. (2004). Influence of pore structure on electric double-layer capacitance of template mesoporous carbons. J. Power Sources 133, 329-336. doi: 10.1016/j.jpowsour.2004.02.013

Fusalba, F., Gouérec, P., Villers, D., and Belanger, D. (2001). Electrochemical characterization of polyaniline in nonaqueous electrolyte and its evaluation as electrode material for electrochemical supercapacitors. J. Electrochem. Soc. 148, A1-A6. doi: 10.1149/1.1339036

Futaba, D. N., Hata, K., Yamada, T., Hiraoka, T., Hayamizu, Y., Kakudate, Y., et al. (2006). Shape-engineerable and highly densely packed single-walled carbon nanotubes and their application as super-capacitor electrodes. Nat. Mater. 5, 987-994. doi: 10.1038/nmat1782

Gao, Q., Demarconnay, L., Pineroa, E. R., and Beguin, F. (2012). Exploring the large voltage range of carbon/carbon supercapacitors in aqueous lithium sulfate electrolyte. Energy Environ. Sci. 5, 9611-9617. doi: 10.1039/C2EE $22284 \mathrm{~A}$

Gao, W., Singh, N., Song, L., Liu, Z., Reddy, A. L. M., Ci, L., et al. (2011). Direct laser writing of micro-supercapacitors on hydrated graphite oxide films. Nat. Nanotechnol. 6:496. doi: 10.1038/nnano.2011.110

Ghosh, A., and Lee, Y. H. (2012). Carbon-based electrochemical capacitors. ChemSusChem 5, 480-99. doi: 10.1002/cssc.201100645

Ginting, R. T., Ovhal, M. M., and Kang, J.-W. (2018). A novel design of hybrid transparent electrodes for high performance and ultra-flexible 
bifunctional electrochromic-supercapacitors. Nano Energy 53, 650-657. doi: 10.1016/j.nanoen.2018.09.016

Gogotsi, Y., and Simon, P. (2011). Materials science. True performance metrics in electrochemical energy storage. Science 334, 917-918. doi: $10.1126 /$ science. 1213003

Guo, H., and Gao, Q. (2009). Boron and nitrogen co-doped porous carbon and its enhanced properties as supercapacitor. J. Power Sources 186, 551-556. doi: 10.1016/j.jpowsour.2008.10.024

Gupta, V., and Miura, N. (2006). Polyaniline/single-wall carbon nanotube (PANI/SWCNT) composites for high performance supercapacitors. Electrochim. Acta 52, 1721-1726. doi: 10.1016/j.electacta.2006.01.074

Han, P., Xu, G., Han, X., Zhao, J., Zhou, X., and Cui, G. (2018). Lithium ion capacitors in organic electrolyte system: scientific problems, material development, and key technologies. Adv. Energy Mater. 8, 1801243. doi: 10.1002/aenm.201801243

Han, Y., Lu, Y., Shen, S., Zhong, Y., Liu, S., Xia, X., et al. (2019). Enhancing the capacitive storage performance of carbon fiber textile by surface and structural modulation for advanced flexible asymmetric supercapacitors. Adv. Funct. Mater. 29:3629. doi: 10.1002/adfm.201806329

Heo, Y.-J., Lee, J. W., Son, Y.-R., Lee, J.-H., Yeo, C. S., Lam, T. D., et al. (2018). Large-scale conductive yarns based on twistable Korean traditional paper (Hanji) for supercapacitor applications: toward high-performance paper supercapacitors. Adv. Energy Mater. 8:1854. doi: 10.1002/aenm.201801854

Hsia, B., Marschewski, J., Wang, S., In, J. B., Carraro, C., Poulikakos, D., et al. (2014). Highly flexible, all solid-state micro-supercapacitors from vertically aligned carbon nanotubes. Nanotechnology 25:055401. doi: 10.1088/0957-4484/25/5/055401

Hsieh, C.-T., and Teng, H. (2002). Influence of oxygen treatment on electric double-layer capacitance of activated carbon fabrics. Carbon 40, 667-674. doi: 10.1016/S0008-6223(01)00182-8

Hu, L., Pasta, M., La Mantia, F., Cui, L., Jeong, S., Deshazer, H. D., et al. (2010). Stretchable, porous, and conductive energy textiles. Nano Lett. 10, 708-714. doi: $10.1021 / \mathrm{nl} 903949 \mathrm{~m}$

Huang, H. S., Chang, K. H., Suzuki, N., Yamauchi, Y., Hu, C. C., and Wu, K. C. (2013). Evaporation-induced coating of hydrous ruthenium oxide on mesoporous silica nanoparticles to develop high-performance supercapacitors. Small 9, 2520-2526. doi: 10.1002/smll.201202786

Huang, J., Wei, J., Xu, Y., Xiao, Y., and Chen, Y. (2017). A pineconeinspired hierarchical vertically aligned nanosheet array electrode for highperformance asymmetric supercapacitors. J. Mater. Chem. A 5, 23349-23360. doi: $10.1039 / \mathrm{c} 7 \mathrm{ta} 07868 \mathrm{~d}$

Huang, W., Humphrey, B. D., and MacDiarmid, A. G. (1986). Polyaniline, a novel conducting polymer. Morphology and chemistry of its oxidation and reduction in aqueous electrolytes. J. Chem. Soc. Faraday Trans. 1 Phys. Chem. Condens. Phases 82, 2385-2400. doi: 10.1039/F19868202385

Hulicova-Jurcakova, D., Puziy, A. M., Poddubnaya, O. I., Suárez-García, F., Tascón, J. M., and Lu, G. Q. (2009a). Highly stable performance of supercapacitors from phosphorus-enriched carbons. J. Am. Chem. Soc. 131, 5026-5027. doi: 10.1021/ja809265m

Hulicova-Jurcakova, D., Seredych, M., Lu, G. Q., and Bandosz, T. J. (2009b). Combined effect of nitrogen- and oxygen-containing functional groups of microporous activated carbon on its electrochemical performance in supercapacitors. Adv. Funct. Mater. 19, 438-447. doi: 10.1002/adfm. 200801236

Hulicova-Jurcakova, D., Seredych, M., Lu, G. Q., Kodiweera, N. K., Stallworth, P. E., Greenbaum, S., et al. (2009c). Effect of surface phosphorus functionalities of activated carbons containing oxygen and nitrogen on electrochemical capacitance. Carbon 47, 1576-1584. doi: 10.1016/j.carbon.2009.02.006

Inagaki, M., Konno, H., and Tanaike, O. (2010). Carbon materials for electrochemical capacitors. J. Power Sources 195, 7880-7903. doi: 10.1016/j.jpowsour.2010.06.036

Inagaki, M., Toyoda, M., Soneda, Y., and Morishita, T. (2018). Nitrogen-doped carbon materials. Carbon 132, 104-140. doi: 10.1016/j.carbon.2018.02.024

Itoi, H., Nishihara, H., Ishii, T., Nueangnoraj, K., Berenguer-Betrian, R., and Kyotani, T. (2014). Large pseudocapacitance in quinonefunctionalized zeolite-templated carbon. Bull. Chem. Soc. Jpn. 87, 250-257. doi: 10.1246/bcsj.20130292
Itoi, H., Nishihara, H., Kogure, T., and Kyotani, T. (2011). Three-dimensionally arrayed and mutually connected 1.2-nm nanopores for high-performance electric double layer capacitor. J. Am. Chem. Soc. 133, 1165-1167. doi: 10.1021/ja108315p

Jiang, J., Li, Y., Liu, J., Huang, X., Yuan, C., and Lou, X. W. (2012). Recent advances in metal oxide-based electrode architecture design for electrochemical energy storage. Adv. Mater. 24, 5166-5180. doi: 10.1002/adma.201202146

Jiang, L., Yan, J., Xue, R., Sun, G., and Yi, B. (2014). Partially graphitized ordered mesoporous carbons for high-rate supercapacitors. J. Solid State Electrochem. 18, 2175-2182. doi: 10.1007/s10008-014-2458-3

Kang, E., Jeon, G., and Kim, J. K. (2013). Free-standing, well-aligned ordered mesoporous carbon nanofibers on current collectors for high-power micro-supercapacitors. Chem. Commun. 49, 6406-6408. doi: 10.1039/C3CC $42436 \mathrm{G}$

Kim, D. K., Bong, S., Jin, X., Seong, K. D., Hwang, M., Kim, N. D., et al. (2019). Facile in situ synthesis of multiple-heteroatom-doped carbons derived from polyimide precursors for flexible all-solid-state supercapacitors. ACS Appl. Mater. Interfaces 11, 1996-2005. doi: 10.1021/acsami.8b15162

Kim, D. K., Kim, N. D., Park, S.-K., Seong, K.-D., Hwang, M., You, N.-H., et al. (2018). Nitrogen doped carbon derived from polyimide/multiwall carbon nanotube composites for high performance flexible all-solid-state supercapacitors. J. Power Sources 380, 55-63. doi: 10.1016/j.jpowsour.2018.01.069

Kim, J. H., Nam, K. W., Ma, S. B., and Kim, K. B. (2006). Fabrication and electrochemical properties of carbon nanotube film electrodes. Carbon 44, 1963-1968. doi: 10.1016/j.carbon.2006.02.002

Kim, K.-S., and Park, S.-J. (2012). Easy synthesis of polyaniline-based mesoporous carbons and their high electrochemical performance. Microporous Mesoporous Mater. 163, 140-146. doi: 10.1016/j.micromeso.2012.04.047

Kim, M. S., Lim, E., Kim, S., Jo, C., Chun, J., and Lee, J. (2017). General synthesis of $\mathrm{N}$-doped macroporous graphene-encapsulated mesoporous metal oxides and their application as new anode materials for sodiumion hybrid supercapacitors. Adv. Funct. Mater. 27:1603921. doi: 10.1002/ adfm.201603921

Kinage, A. K., Upare, P. P., Shivarkar, A. B., and Gupte, S. P. (2011). Highly regioselective synthesis of $\beta$-amino alcohol by reaction with aniline and propylene carbonate in self solvent system over large pore zeolite catalyst. Green Sustain. Chem. 1, 76-84. doi: 10.4236/gsc.2011.13013

Konno, H., Ito, T., Ushiro, M., Fushimi, K., and Azumi, K. (2010). High capacitance B/C/N composites for capacitor electrodes synthesized by a simple method. J. Power Sources 195, 1739-1746. doi: 10.1016/j.jpowsour.2009.09.072

Kordás, K., Mustonen, T., Tóth, G., Jantunen, H., Lajunen, M., Soldano, C., et al. (2006). Inkjet printing of electrically conductive patterns of carbon nanotubes. Small 2, 1021-1025. doi: 10.1002/smll.200600061

Kruk, M., Dufour, B., Celer, E. B., Kowalewski, T., Jaroniec, M., and Matyjaszewski, K. (2005). Synthesis of mesoporous carbons using ordered and disordered mesoporous silica templates and polyacrylonitrile as carbon precursor. J. Phys. Chem. B 109, 9216-9225. doi: 10.1021/jp045594x

Kuroki, S., Hosaka, Y., and Yamauchi, C. (2013). A solid-state NMR study of the carbonization of polyaniline. Carbon 55, 160-167. doi: 10.1016/j.carbon.2012.12.022

Kwon, T., Nishihara, H., Itoi, H., Yang, Q.-H., and Kyotani, T. (2009). Enhancement mechanism of electrochemical capacitance in nitrogen/boron-doped carbons with uniform straight nanochannels. Langmuir 25, 11961-11968. doi: 10.1021/la901318d

Kyotani, T., Nagai, T., Inoue, S., and Tomita, A. (1997). Formation of new type of porous carbon by carbonization in zeolite nanochannels. Chem. Mater. 9, 609-615. doi: 10.1021/cm960430h

Lai, F., Feng, J., Yan, R., Wang, G.-C., Antonietti, M., and Oschatz, M. (2018). Breaking the limits of ionic liquid-based supercapacitors: mesoporous carbon electrodes functionalized with manganese oxide nanosplotches for dense, stable, and wide-temperature energy storage. Adv. Funct. Mater. 28:1801298. doi: 10.1002/adfm.201801298

Lallave, M., Bedia, J., Ruiz-Rosas, R., Rodríguez-Mirasol, J., Cordero, T., Otero, J. C., et al. (2007). Filled and hollow carbon nanofibers by coaxial electrospinning of alcell lignin without binder polymers. Adv. Mater. 19, 4292-4296. doi: 10.1002/adma.200700963 
Lam, D. V., Jo, K., Kim, C.-H., Kim, J.-H., Lee, H.-J., and Lee, S.-M. (2016). Activated carbon textile via chemistry of metal extraction for supercapacitors. ACS Nano 10, 11351-11359. doi: 10.1021/acsnano.6b06608

Largeot, C., and Portet, C. (2008). Relation between the ion size and pore size for an electric double-layer capacitor. J. Am. Chem. Soc. 130, 2730-2731. doi: $10.1021 /$ ja7106178

Lawes, S., Riese, A., Sun, Q., Cheng, N., and Sun, X. (2015). Printing nanostructured carbon for energy storage and conversion applications. Carbon 92, 150-176. doi: 10.1016/j.carbon.2015.04.008

Le, L. T., Ervin, M. H., Qiu, H., Fuchs, B. E., and Lee, W. Y. (2011). Graphene supercapacitor electrodes fabricated by inkjet printing and thermal reduction of graphene oxide. Electrochem. Commun. 13, 355-358. doi: 10.1016/j.elecom.2011.01.023

Lee, J. S., Kim, S. I., Yoon, J. C., and Jang, J. H. (2013). Chemical vapor deposition of mesoporous graphene nanoballs for supercapacitor. ACS Nano 7, 6047-6055. doi: $10.1021 / \mathrm{nn} 401850 \mathrm{z}$

Lee, S.-W., Park, D. K., Lee, J. K., Ju, J. B., and Sohn, T. W. (2001). Discharge capacitance of electric double layer capacitor with electrodes made of carbon nanotubes directly deposited on SUS304 plates. Korean J. Chem Eng. 18, 371-375. doi: 10.1007/BF02699180

Lee, Y. H., Chang, K. H., and Hu, C. C. (2013). Differentiate the pseudocapacitance and double-layer capacitance contributions for nitrogen-doped reduced graphene oxide in acidic and alkaline electrolytes. J. Power Sources 227, 300-308. doi: 10.1016/j.jpowsour.2012.11.026

Lei, Z., Christov, N., Zhang, L. L., and Zhao, X. S. (2011). Mesoporous carbon nanospheres with an excellent electrocapacitive performance. J. Mater. Chem. 21, 2274-2281. doi: 10.1039/C0JM03322G

Leyva-García, S., Lozano-Castelló, D., Morallón, E., and Cazorla-Amorós, D. (2016a). Silica-templated ordered mesoporous carbon thin films as electrodes for micro-capacitors. J. Mater. Chem. A 3, 4570-4579. doi: 10.1039/C5TA10552H

Leyva-García, S., Lozano-Castelló, D., Morallón, E., Vogl, T., Schütter, C., Passerini, S., et al. (2016b). Electrochemical performance of a superporous activated carbon in ionic liquid-based electrolytes. J. Power Sources 336, 419-426. doi: 10.1016/j.jpowsour.2016.11.010

Li, H., Liang, J., Li, H., Zheng, X., Tao, Y., Huang, Z. H., et al. (2019). Activated carbon fibers with manganese dioxide coating for flexible fiber supercapacitors with high capacitive performance. J. Energy Chem. 31, 95-100. doi: 10.1016/j.jechem.2018.05.008

Li, H.-Q., Luo, J.-Y., Zhou, X.-F., Yu, C.-Z., and Xia, Y.-Y. (2007). An ordered mesoporous carbon with short pore length and its electrochemical performances in supercapacitor applications. J. Electrochem. Soc. 154, A731A736. doi: 10.1149/1.2741198

Li, J., Li, H., Li, J., Wu, G., Shao, Y., Li, Y., et al. (2018). A single-walled carbon nanotubes/poly(3,4-ethylenedioxythiophene)poly(styrenesulfonate)/copper hexacyanoferrate hybrid film for highvolumetric performance flexible supercapacitors. J. Power Sources 386, 96-105. doi: 10.1016/j.jpowsour.2018.03.046

Li, M., Liu, C., Cao, H., Zhao, H., Zhang, Y., and Fan, Z. (2014). KOH selftemplating synthesis of three-dimensional hierarchical porous carbon materials for high performance supercapacitors. J. Mater. Chem. A 2, 14844-14851. doi: 10.1039/C4TA02167C

Li, S., Yu, C., Yang, J., Zhao, C., Fan, X., Huang, H., et al. (2017). Ultrathin nitrogen-enriched hybrid carbon nanosheets for supercapacitors with ultrahigh rate performance and high energy density. ChemElectroChem 4, 369-375. doi: 10.1002/celc.201600614

Li, W., Zhang, F., Dou, Y., Wu, Z., Liu, H., Qian, X., et al. (2011). A self-template strategy for the synthesis of mesoporous carbon nanofibers as advanced supercapacitor electrodes. Adv. Energy Mater. 1, 382-386. doi: 10.1002/aenm.201000096

Liang, T., Wang, H., Xu, D., Liao, K., Wang, R., He, B., et al. (2018). High-energy flexible quasi-solid-state lithium-ion capacitors enabled by a freestanding rGOencapsulated Fe3O4 nanocube anode and a holey rGO film cathode. Nanoscale 10, 17814-17823. doi: 10.1039/C8NR04292F

Lin, J., Peng, Z., Liu, Y., Ruiz-Zepeda, F., Ye, R., Samuel, E. L., et al. (2014). Laserinduced porous graphene films from commercial polymers. Nat. Commun. 5:6714. doi: $10.1038 /$ ncomms6714
Liu, C.-L., Dong, W., Cao, G., Song, J., Liu, L., and Yang, Y. (2008). Capacitance limits of activated carbon fiber electrodes in aqueous electrolyte. J. Electrochem. Soc. 155, F1-F7. doi: 10.1149/1.2799683

Liu, H.-J., Wang, X.-M., Cui, W.-J., Dou, Y.-Q., Zhao, D.-Y., and Xia, Y.-Y. (2010). Highly ordered mesoporous carbon nanofiber arrays from a crab shell biological template and its application in supercapacitors and fuel cells. J. Mater. Chem. 20, 4223-4230. doi: 10.1039/B925776D

Liu, H. J., Cui, W. J., Jin, L. H., Wang, C. X., and Xia, Y. Y. (2009). Preparation of three-dimensional ordered mesoporous carbon sphere arrays by a two-step templating route and their application for supercapacitors. J. Mater. Chem. 19, 3661-3667. doi: 10.1039/B819820A

Liu, H. J., Wang, J., Wang, C. X., and Xia, Y. Y. (2011). Ordered hierarchical mesoporous/microporous carbon derived from mesoporous titanium-carbide/carbon composites and its electrochemical performance in supercapacitor. Adv. Energy Mater. 1, 1101-1108. doi: 10.1002/aenm.201100255

Liu, L., Yu, Y., Yan, C., Li, K., and Zheng, Z. (2015). Wearable energy-dense and power-dense supercapacitor yarns enabled by scalable graphene-metallic textile composite electrodes. Nat. Commun. 6:7260. doi: 10.1038/ncomms8260

Liu, R., Ma, L., Niu, G., Li, X., Li, E., Bai, Y., et al. (2017). Oxygendeficient bismuth oxide/graphene of ultrahigh capacitance as advanced flexible anode for asymmetric supercapacitors. Adv. Funct. Mater. 27:1635. doi: 10.1002/adfm.201701635

Liu, Z., Fu, X., Li, M., Wang, F., Wang, Q., Kang, G., et al. (2015). Novel silicondoped, silicon and nitrogen-codoped carbon nanomaterials with high activity for the oxygen reduction reaction in alkaline medium. J. Mater. Chem. A 3, 3289-3293. doi: 10.1039/C4TA05937A

Lota, G., and Frackowiak, E. (2009). Striking capacitance of carbon/iodide interface. Electrochem. Commun. 11, 87-90. doi: 10.1016/j.elecom.2008.10.026

Lota, G., Grzyb, B., Machnikowska, H., Machnikowski, J., and Frackowiak, E. (2005). Effect of nitrogen in carbon electrode on the supercapacitor performance. Chem. Phys. Lett. 404, 53-58. doi: 10.1016/j.cplett.2005.01.074

Lozano-Castelló, D., Lillo-Ródenas, M. A., Cazorla-Amorós, D., and LinaresSolano, A. (2001). Preparation of activated carbons from Spanish anthracite - I. Activation by KOH. Carbon 39, 741-749. doi: 10.1016/S0008-6223(00) 00185-8

Ma, G., Li, J., Sun, K., Peng, H., Mu, J., and Lei, Z. (2014). High performance solid-state supercapacitor with PVA-KOH-K $3\left[\mathrm{Fe}(\mathrm{CN})_{6}\right]$ gel polymer as electrolyte and separator. J. Power Sources 256, 281-287. doi: 10.1016/j.jpowsour.2014.01.062

Ma, W., Chen, S., Yang, S., Chen, W., Weng, W., Cheng, Y., et al. (2017). Flexible all-solid-state asymmetric supercapacitor based on transition metal oxide nanorods/reduced graphene oxide hybrid fibers with high energy density. Carbon 113, 151-158. doi: 10.1016/j.carbon.2016.11.051

Martins, V. L., Rennie, A. J. R., Sanchez-Ramirez, N., Torresi, R. M., and Hall, P. J. (2018). Improved performance of ionic liquid supercapacitors by using tetracyanoborate anions. ChemElectroChem 5, 598-604. doi: 10.1002/celc. 201701164

Meng, C., Liu, C., Chen, L., Hu, C., and Fan, S. (2010). Highly flexible and all-solid-state paperlike polymer supercapacitors. Nano Lett. 10, 4025-4031. doi: $10.1021 / \mathrm{nl} 1019672$

Miao, F., Shao, C., Li, X., Wang, K., and Liu, Y. (2016). Flexible solidstate supercapacitors based on freestanding nitrogen-doped porous carbon nanofibers derived from electrospun polyacrylonitrile@polyaniline nanofibers. J. Mater. Chem. A 4, 4180-4187. doi: 10.1039/C6TA00015K

Miller, J. R. (2016). Engineering electrochemical capacitor applications. J. Power Sources 326, 726-735. doi: 10.1016/j.jpowsour.2016.04.020

Miller, J. R., and Outlaw, R. A. (2015). Vertically-oriented graphene electric double layer capacitor designs. J. Electrochem. Soc. 162, A5077-A5082. doi: 10.1149/2.0121505jes

Mini, P. A., Balakrishnan, A., Nair, S. V., and Subramanian, K. R., V (2011). Highly super capacitive electrodes made of graphene/poly(pyrrole). Chem. Commun. 47, 5753-5755. doi: 10.1039/c1cc00119a

Mostazo-López, M. J., Ruiz-Rosas, R., Castro-Muñiz, A., Nishihara, H., Kyotani, T., Morallón, E., et al. (2018). Ultraporous nitrogen-doped zeolite-templated carbon for high power density aqueous-based supercapacitors. Carbon 129, 510-519. doi: 10.1016/j.carbon.2017.12.050 
Mostazo-López, M. J., Ruiz-Rosas, R., Morallón, E., and CazorlaAmorós, D. (2015). Generation of nitrogen functionalities on activated carbons by amidation reactions and Hofmann rearrangement: chemical and electrochemical characterization. Carbon 91, 252-265. doi: 10.1016/j.carbon.2015.04.089

Mostazo-López, M. J., Ruiz-Rosas, R., Morallón, E., and Cazorla-Amorós, D. (2016). Nitrogen doped superporous carbon prepared by a mild method. Enhancement of supercapacitor performance. Int. J. Hydrogen Energy 41, 19691-19701. doi: 10.1016/j.ijhydene.2016.03.091

Muzaffar, A., Ahamed, M. B., Deshmukh, K., and Thirumalai, J. (2019). A review on recent advances in hybrid supercapacitors: design, fabrication and applications. Renew. Sustain. Energy Rev. 101, 123-145. doi: 10.1016/j.rser.2018.10.026

Na, W., Jun, J., Park, J. W., Lee, G., and Jang, J. (2017). Highly porous carbon nanofibers co-doped with fluorine and nitrogen for outstanding supercapacitor performance. J. Mater. Chem. A 5, 17379-17387. doi: 10.1039/C7TA04406B

Nakamura, T., Yamada, Y., and Yano, K. (2006). Three-dimensionally ordered array of nanoporous starburst carbon spheres. Chem. Lett. 35, 1436-1437. doi: $10.1246 / \mathrm{cl} .2006 .1436$

Naoi, K., Ishimoto, S., Miyamoto, J., and Naoi, W. (2012). Second generation 'nanohybrid supercapacitor': evolution of capacitive energy storage devices. Energy Environ. Sci. 5, 9363-9373. doi: 10.1039/C2EE21675B

Nishihara, H., and Kyotani, T. (2012). Templated nanocarbons for energy storage. Adv. Mater. 24, 4473-4498. doi: 10.1002/adma.201201715

Nomura, K., Nishihara, H., Kobayashi, N., Asada, T., and Kyotani, T. (2019). $4.4 \mathrm{~V}$ supercapacitors based on super-stable mesoporous carbon sheet made of edge-free graphene walls. Energy Environ. Sci. doi: 10.1039/C8EE03184C

Nueangnoraj, K., Nishihara, H., Ishii, T., Yamamoto, N., Itoi, H., Berenguer, R., et al. (2015). Pseudocapacitance of zeolite-templated carbon in organic electrolytes. Energy Storage Mater. 1, 35-41. doi: 10.1016/j.ensm.2015.08.003

Nueangnoraj, K., Ruiz-Rosas, R., Nishihara, H., Shiraishi, S., Morallón, E., CazorlaAmorós, D., et al. (2014). Carbon-carbon asymmetric aqueous capacitor by pseudocapacitive positive and stable negative electrodes. Carbon 67, 792-794. doi: 10.1016/j.carbon.2013.10.011

Nyholm, L., Nyström, G., Mihranyan, A., and Strømme, M. (2011). Toward flexible polymer and paper-based energy storage devices. Adv. Mater. 23, 3751-3769. doi: 10.1002/adma.201004134

Ornelas, O., Sieben, J. M., Ruiz-Rosas, R., Morallón, E., Cazorla-Amorós, D., Geng, J., et al. (2014). On the origin of the high capacitance of nitrogen-containing carbon nanotubes in acidic and alkaline electrolytes. Chem. Commun. 50, 11343-11346. doi: 10.1039/C4CC04876H

Oschatz, M., Borchardt, L., Hippauf, F., Nickel, W., Kaskel, S., and Brunner, E. (2016). "Interactions between electrolytes and carbon-based materials-NMR studies on electrical double-layer capacitors, lithium-ion batteries, and fuel cells," in Annual Reports on NMR Spectroscopy, ed G. A. Webb (London, UK: Elsevier Ltd.), 237-318. doi: 10.1016/bs.arnmr.2015.08.003

Ou, T.-M., Hsu, C.-T., and Hu, C.-C. (2015). Synthesis and characterization of sodium-doped $\mathrm{MnO}_{2}$ for the aqueous asymmetric supercapacitor application. J. Electrochem. Soc. 162, A5124-A5132. doi: 10.1149/2.0191505jes

Park, J. H., Ko, J. M., and Ok Park, O. (2003). Carbon nanotube/ $\mathrm{RuO}_{2}$ nanocomposite electrodes for supercapacitors. J. Electrochem. Soc. 150:A864. doi: $10.1149 / 1.1576222$

Park, J. H., and Park, O. O. (2002). Hybrid electrochemical capacitors based on polyaniline and activated carbon electrodes. J. Power Sources 111, 185-190. doi: 10.1016/S0378-7753(02)00304-X

Park, S., Vosguerichian, M., and Bao, Z. (2013). A review of fabrication and applications of carbon nanotube film-based flexible electronics. Nanoscale 5, 1727-1752. doi: 10.1039/C3NR33560G

Pech, D., Brunet, M., Taberna, P. L., Simon, P., Fabre, N., Mesnilgrente, F., et al. (2010). Elaboration of a microstructured inkjet-printed carbon electrochemical capacitor. J. Power Sources 195, 1266-1269. doi: 10.1016/j.jpowsour.2009.08.085

Peng, C., Zhang, S., Zhou, X., and Chen, G. Z. (2010). Unequalisation of electrode capacitances for enhanced energy capacity in asymmetrical supercapacitors. Energy Environ. Sci. 3, 1499-1502. doi: 10.1039/C0EE00228C

Piñeiro-Prado, I., Salinas-Torres, D., Ruiz-Rosas, R., Morallón, E., and CazorlaAmorós, D. (2016). Design of activated carbon/activated carbon asymmetric capacitors. Front. Mater. 3, 1-12. doi: 10.3389/fmats.2016.00016
Qie, L., Chen, W., Xu, H., Xiong, X., Jiang, Y., Zou, F., et al. (2013). Synthesis of functionalized 3D hierarchical porous carbon for highperformance supercapacitors. Energy Environ. Sci. 6, 2497-2504. doi: 10.1039/ C3EE41638K

Quesada-Plata, F., Ruiz-Rosas, R., Morallón, E., and Cazorla-Amorós, D. (2016). Activated carbons prepared through $\mathrm{H}_{3} \mathrm{PO}_{4}$-assisted hydrothermal carbonisation from biomass wastes: porous texture and electrochemical performance. ChemPlusChem 81, 1349-1359. doi: 10.1002/cplu.201600412

Quílez-Bermejo, J., González-Gaitán, C., Morallón, E., and Cazorla-Amorós, D. (2017). Effect of carbonization conditions of polyaniline on its catalytic activity towards ORR. Some insights about the nature of the active sites. Carbon 119, 62-71. doi: 10.1016/j.carbon.2017.04.015

Rakhi, R. B., Chen, W., Cha, D., and Alshareef, H. N. (2011). High performance supercapacitors using metal oxide anchored graphene nanosheet electrodes. $J$. Mater. Chem. 21, 16197. doi: 10.1039/C1JM12963E

Ravi, S., and Vadukumpully, S. (2015). Sustainable carbon nanomaterials: recent advances and its applications in energy and environmental remediation. $J$. Environ. Chem. Eng. 4, 835-856. doi: 10.1016/j.jece.2015.11.026

Raymundo-Piñero, E., Cazorla-Amorós, D., Linares-Solano, A., Find, J., Wild, U., and Schlögl, R. (2002). Structural characterization of N-containing activated carbon fibers prepared from a low softening point petroleum pitch and a melamine resin. Carbon 40, 597-608. doi: 10.1016/S0008-6223(01)00155-5

Ren, L., Zhang, G., Yan, Z., Kang, L., Xu, H., Shi, F., et al. (2017). High capacitive property for supercapacitor using $\mathrm{Fe}^{3+} / \mathrm{Fe}^{2+}$ redox couple additive electrolyte. Electrochim. Acta 231, 705-712. doi: 10.1016/j.electacta.2017.02.056

Román-Martínez, M. C., Cazorla-Amorós, D., Linares-Solano, A., and de Lecea, C. S.-M. (1993). TPD and TPR characterization of carbonaceous supports and Pt/C catalysts. Carbon 31, 895-902. doi: 10.1016/0008-6223(93)90190-L

Rosas, J. M., Berenguer, R., Valero-Romero, M. J., Rodríguez-Mirasol, J., and Cordero, T. (2014). Preparation of different carbon materials by thermochemical conversion of lignin. Front. Mater. 1, 1-17. doi: 10.3389/fmats.2014.00029

Rosas, J. M., Ruiz-Rosas, R. R., Berenguer, R., Cazorla-Amorós, D., Morallon, E., Nishihara, H., et al. (2016). Easy fabrication of superporous zeolite templated carbon electrodes by electrospray on rigid and flexible substrates. J. Mater. Chem. A 4610-4618. doi: 10.1039/C6TA00241B

Rozlívková, Z., Trchová, M., Exnerová, M., and Stejskal, J. (2011). The carbonization of granular polyaniline to produce nitrogen-containing carbon. Synth. Met. 161, 1122-1129. doi: 10.1016/j.synthmet.2011.03.034

Ruiz-Rosas, R., Valero-Romero, M. J., Salinas-Torres, D., RodríguezMirasol, J., Cordero, T., Morallón, E., et al. (2014). Electrochemical performance of hierarchical porous carbon materials obtained from the infiltration of lignin into zeolite templates. ChemSusChem 7, 1458-1467. doi: $10.1002 /$ cssc. 201301408

Salinas-Torres, D., Ruiz-Rosas, R., Valero-Romero, M. J., Rodríguez-Mirasol, J., Cordero, T., Morallón, E., et al. (2016). Asymmetric capacitors using lignin-based hierarchical porous carbons. J. Power Sources 326, 641-651. doi: 10.1016/j.jpowsour.2016.03.096

Salinas-Torres, D., Shiraishi, S., Morallón, E., and Cazorla-Amorós, D. (2015). Improvement of carbon materials performance by nitrogen functional groups in electrochemical capacitors in organic electrolyte at severe conditions. Carbon 82, 205-213. doi: 10.1016/j.carbon.2014.10.064

Salinas-Torres, D., Sieben, J. M., Lozano-Castelló, D., Cazorla-Amorós, D., and Morallón, E. (2013). Asymmetric hybrid capacitors based on activated carbon and activated carbon fibre-PANI electrodes. Electrochim. Acta 89, 326-333. doi: 10.1016/j.electacta.2012.11.039

Salinas-Torres, D., Sieben, J. M., Lozano-Castello, D., Morallón, E., Burghammer, M., Riekel, C., et al. (2012). Characterization of activated carbon fiber/polyaniline materials by position-resolved microbeam small-angle X-ray scattering. Carbon 50, 1051-1056. doi: 10.1016/j.carbon.2011.10.010

Salunkhe, R. R., Lee, Y. H., Chang, K. H., Li, J. M., Simon, P., Tang, J., et al. (2014). Nanoarchitectured graphene-based supercapacitors for nextgeneration energy-storage applications. Chem. A Eur. J. 20, 13838-13852. doi: 10.1002/chem.201403649

Schütter, C., Husch, T., Viswanathan, V., Passerini, S., Balducci, A., and Korth, M. (2016). Rational design of new electrolyte materials for electrochemical double layer capacitors. J. Power Sources 326, 541-548. doi: 10.1016/j.jpowsour.2016.06.022 
Seredych, M., Hulicova-Jurcakova, D., Lu, G. Q., and Bandosz, T. J. (2008). Surface functional groups of carbons and the effects of their chemical character, density and accessibility to ions on electrochemical performance. Carbon 46, 1475-1488. doi: 10.1016/j.carbon.2008.06.027

Sevilla, M., and Mokaya, R. (2014). Energy storage applications of activated carbons: supercapacitors and hydrogen storage. Energy Environ. Sci. 7, 1250-1280. doi: 10.1039/C3EE43525C

Shen, B., Zhang, X., Guo, R., Lang, J., Chen, J., and Yan, X. (2016). Carbon encapsulated $\mathrm{RuO} 2$ nano-dots anchoring on graphene as an electrode for asymmetric supercapacitors with ultralong cycle life in an ionic liquid electrolyte. J. Mater. Chem. A 4, 8180-8189. doi: 10.1039/C6TA02473D

Shen, W., and Fan, W. (2013). Nitrogen-containing porous carbons: synthesis and application. J. Mater. Chem. A 1, 999-1013. doi: 10.1039/C2TA00028H

Shi, S., Xu, C., Yang, C., Li, J., Du, H., Li, B., et al. (2013). Flexible supercapacitors. Particuology 11, 371-377. doi: 10.1016/j.partic.2012.12.004

Simon, P., and Burke, A. (2008). Nanostructured carbons: double-layer capacitance and more. Electrochem. Soc. Interface 17, 38-43.

Simon, P., and Gogotsi, Y. (2008). Materials for electrochemical capacitors. Nat. Mater. 7, 845-854. doi: 10.1038/nmat2297

Sivakkumar, S. R., and Pandolfo, A. G. (2012). Evaluation of lithium-ion capacitors assembled with pre-lithiated graphite anode and activated carbon cathode. Electrochim. Acta 65, 280-287. doi: 10.1016/j.electacta.2012.01.076

Snook, G. A., Kao, P., and Best, A. S. (2011). Conducting-polymer-based supercapacitor devices and electrodes. J. Power Sources 196, 1-12. doi: 10.1016/j.jpowsour.2010.06.084

Snook, G. A., Wilson, G. J., and Pandolfo, A. G. (2009). Mathematical functions for optimisation of conducting polymer/activated carbon asymmetric supercapacitors. J. Power Sources 186, 216-223. doi: 10.1016/j.jpowsour.2008.09.085

Stoller, M. D., and Ruoff, R. S. (2010). Best practice methods for determining an electrode material's performance for ultracapacitors. Energy Environ. Sci. 3, 1294-1301. doi: 10.1039/C0EE00074D

Su, F., Poh, C. K., Chen, J. S., Xu, G., Wang, D., Li, Q., et al. (2011). Nitrogencontaining microporous carbon nanospheres with improved capacitive properties. Energy Environ. Sci. 4, 717-724. doi: 10.1039/C0EE00277A

Su, H., Zhang, H., Liu, F., Chun, F., Zhang, B., Chu, X., et al. (2017). High power supercapacitors based on hierarchically porous sheet-like nanocarbons with ionic liquid electrolytes. Chem. Eng. J. 322, 73-81. doi: 10.1016/j.cej.2017.04.012

Sugimoto, W., Shibutani, T., Murakami, Y., and Takasu, Y. (2002). Charge storage capabilities of rutile-type $\mathrm{RuO}_{2}-\mathrm{VO}_{2}$ solid solution for electrochemical supercapacitors. Electrochem. Solid-State Lett. 5, A170-A172. doi: $10.1149 / 1.1483155$

Sun, L., Tian, C., Fu, Y., Yang, Y., Yin, J., Wang, L., et al. (2014). Nitrogendoped porous graphitic carbon as an excellent electrode material for advanced supercapacitors. Chem. A Eur. J. 20, 564-574. doi: 10.1002/chem.201303345

Takasu, Y., and Murakami, Y. (2000). Design of oxide electrodes with large surface area. Electrochim. Acta 45, 4135-4141. doi: 10.1016/S0013-4686(00)00534-X

Tang, H., Yang, C., Lin, Z., Yang, Q., Kang, F., and Wong, C. P. (2015). Electrospray-deposition of graphene electrodes: a simple technique to build high-performance supercapacitors. 7, 9133-9139. doi: 10.1039/C5NR00465A

Tomko, T., Rajagopalan, R., Aksoy, P., and Foley, H. C. (2011). Synthesis of boron/nitrogen substituted carbons for aqueous asymmetric capacitors. Electrochim. Acta 56, 5369-5375. doi: 10.1016/j.electacta.2011.03.112

Valero-Romero, M. J., Márquez-Franco, E. M., Bedia, J., Rodríguez-Mirasol, J., and Cordero, T. (2014). Hierarchical porous carbons by liquid phase impregnation of zeolite templates with lignin solution. Microporous Mesoporous Mater. 196, 68-78. doi: 10.1016/j.micromeso.2014.04.055

Vlad, A., Singh, N., Melinte, S., Gohy, J.-F., and Ajayan, P. M. (2016). Carbon redox-polymer-gel hybrid supercapacitors. Sci. Rep. 6:22194. doi: $10.1038 /$ srep 22194

Wang, D.-W., Li, F., Liu, M., Lu, G. Q., and Cheng, H.-M. (2008). 3D aperiodic hierarchical porous graphitic carbon material for high-rate electrochemical capacitive energy storage. Angew. Chem. Int. Ed. 47, 373-376. doi: $10.1002 /$ anie. 200702721

Wang, G., Zhang, L., and Zhang, J. (2012). A review of electrode materials for electrochemical supercapacitors. Chem. Soc. Rev. 41, 797-828. doi: 10.1039/C1CS15060J
Wang, K. X., Birjukovs, P., Erts, D., Phelan, R., Morris, M. A., Zhou, H. S., et al. (2009). Synthesis and characterisation of ordered arrays of mesoporous carbon nanofibres. J. Mater. Chem. 19, 1331-1338. doi: 10.1039/B817156D

Wang, X., Liu, C.-G., Neff, D., Fulvio, P. F., Mayes, R. T., Zhamu, A., et al. (2013). Nitrogen-enriched ordered mesoporous carbons through direct pyrolysis in ammonia with enhanced capacitive performance. J. Mater. Chem. A 1, 7920-7926. doi: 10.1039/c3ta11342f

Wang, X., and Shi, G. (2015). Flexible graphene devices related to energy conversion and storage. Energy Environ. Sci. 8, 790-823. doi: 10.1039/C4EE03685A

Wang, Y., Li, X., Wang, Y., Liu, Y., Bai, Y., Liu, R., et al. (2019). High-performance flexible MnO 2 @carbonized cotton textile electrodes for enlarged operating potential window symmetrical supercapacitors. Electrochim. Acta 299, 12-18. doi: 10.1016/j.electacta.2018.12.181

Wei, X., Jiang, X., Wei, J., and Gao, S. (2016). Functional groups and pore size distribution do matter to hierarchically porous carbons as high-rate-performance supercapacitors. Chem. Mater. 28, 445-458. doi: 10.1021 /acs.chemmater.5b02336

Wen, Y., Rufford, T. E., Hulicova-Jurcakova, D., and Wang, L. (2016). Nitrogen and phosphorous co-doped graphene monolith for supercapacitors. ChemSusChem 9, 513-520. doi: 10.1002/ cssc. 201501303

Wu, M., Snook, G. A., Gupta, V., Shaffer, M., Fray, D. J., and Chen, G. Z. (2005). Electrochemical fabrication and capacitance of composite films of carbon nanotubes and polyaniline. J. Mater. Chem. 15, 2297-2303. doi: 10.1039/B418835G

Wu, Q., Xu, Y., Yao, Z., Liu, A., and Shi, G. (2010). Supercapacitors based on flexible graphene/polyaniline nanofiber composite films. ACS Nano 4, 1963-1970. doi: 10.1021/nn1000035

Xia, C., Chen, W., Wang, X., Hedhili, M. N., Wei, N., and Alshareef, H. N. (2015). Highly stable supercapacitors with conducting polymer coreshell electrodes for energy storage applications. Adv. Energy Mater. 5:1805. doi: $10.1002 /$ aenm.201401805

Xia, K., Gao, Q., Jiang, J., and Hu, J. (2008). Hierarchical porous carbons with controlled micropores and mesopores for supercapacitor electrode materials. Carbon 46, 1718-1726. doi: 10.1016/j.carbon.2008.07.018

Xia, Y., and Mokaya, R. (2004). Synthesis of ordered mesoporous carbon and nitrogen-doped carbon materials with graphitic pore walls via a simple chemical vapor deposition method. Adv. Mater. 16, 1553-1558. doi: 10.1002/adma.200400391

Xiang, S., Yang, X., Lin, X., Chang, C., Que, H., and Li, M. (2017). Nitrogen and sulfur co-doped polyurethane-based porous carbon materials as supercapacitors exhibit excellent electrochemical performance. J. Solid State Electrochem. 21, 1457-1465. doi: 10.1007/s10008-017-3505-7

Xiao, H., Wu, Z.-S., Chen, L., Zhou, F., Zheng, S., Ren, W., et al. (2017). One-step device fabrication of phosphorene and graphene interdigital micro-supercapacitors with high energy density. ACS Nano 11, 7284-7292. doi: 10.1021/acsnano.7b03288

Xie, Q., Wu, S., Zhang, Y., and Zhao, P. (2017). Nitrogen-enriched flexible porous carbon/graphene composite cloth as free-standing electrodes for high performance aqueous supercapacitors. J. Electroanal. Chem. 801, 57-64. doi: 10.1016/j.jelechem.2017.07.031

Xin, G., Wang, M., Zhang, W., Song, J., and Zhang, B. (2018). Preparation of high-capacitance N,S co-doped carbon nanospheres with hierarchical pores as supercapacitors. Electrochim. Acta 291, 168-176. doi: 10.1016/j.electacta.2018.08.137

Xu, J., Wu, C., Yan, P., Wang, J., Zhang, R., Zhang, X., et al. (2015). Enhanced electrochemical performance of graphitized carbide-derived carbon in alkaline electrolyte. Electrochim. Acta 174, 411-416. doi: 10.1016/j.electacta.2015. 06.025

Yan, J., Ren, C. E., Maleski, K., Hatter, C. B., Anasori, B., Urbankowski, P., et al. (2017). Flexible MXene/Graphene films for ultrafast supercapacitors with outstanding volumetric capacitance. Adv. Funct. Mater. 27:1264. doi: 10.1002/adfm.201701264

Yan, X., Liu, Y., Fan, X., Jia, X., Yu, Y., and Yang, X. (2014). Nitrogen/phosphorus co-doped nonporous carbon nanofibers for high-performance supercapacitors. J. Power Sources 248, 745-751. doi: 10.1016/j.jpowsour.2013.09.129 
Yan, Z., Ma, L., Zhu, Y., Lahiri, I., Hahm, M. G., Liu, Z., et al. (2013). Threedimensional metal-graphene-nanotube multifunctional hybrid materials. ACS Nano 7, 58-64. doi: 10.1021/nn3015882

Yang, X., Wu, D., Chen, X., and Fu, R. (2010). Nitrogen-enriched nanocarbons with a 3-D continuous mesopore structure from polyacrylonitrile for supercapacitor application. J. Phys. Chem. C 114, 8581-8586. doi: 10.1021/jp101255d

Yang, Z., Tian, J., Yin, Z., Cui, C., Qian, W., and Wei, F. (2019). Carbon nanotube- and graphene-based nanomaterials and applications in high-voltage supercapacitor: a review. Carbon 141, 467-480. doi: 10.1016/j.carbon.2018.10.010

Ye, G., Zhu, D., Zhou, Q., Li, D., Zuo, Y., Duan, X., et al. (2018). One-step electrodeposition method to prepare robust flexible pedot-based films for ultra-stable supercapacitors. ChemElectroChem 5, 1130-1136. doi: 10.1002/celc.201800099

Ye, J.-S., Liu, X., Cui, H. F., Zhang, W.-D., Sheu, F.-S., and Lim, T. M. (2005a). Electrochemical oxidation of multi-walled carbon nanotubes and its application to electrochemical double layer capacitors. Electrochem. Commun. 7, 249-255. doi: 10.1016/ j.elecom.2005.01.008

Ye, J. -S., Cui, H. F., Liu, X., Lim, T. M., Zhang, W. De, and Sheu, F. S. (2005b). Preparation and characterization of aligned carbon nanotuberuthenium oxide nanocomposites for supercapacitors. Small 1, 560-565. doi: $10.1002 /$ smll.200400137

Yoo, J. J., Balakrishnan, K., Huang, J., Meunier, V., Sumpter, B. G., and Strivastava, A. (2011). Ultrathin planar graphene supercapacitors. Nano Lett. 11, 1423-1427. doi: 10.1021/nl200225j

Yoon, B.-J., Jeong, S.-H., Lee, K.-H., Seok Kim, H., Gyung Park, C., and Hun Han, J. (2004). Electrical properties of electrical double layer capacitors with integrated carbon nanotube electrodes. Chem. Phys. Lett. 388, 170-174. doi: 10.1016/j.cplett.2004.02.071

Yoon, Y., Lee, K., Kwon, S., Seo, S., Yoo, H., Kim, S., et al. (2014). Vertical alignments of graphene sheets spatially and densely piled for fast ion diffusion in compact supercapacitors. ACS Nano 8, 4580-4590. doi: 10.1021/nn500150j

Yoshida, N., Hirota, Y., Uchida, Y., Asada, T., Kobayashi, N., and Nishiyama, N. (2018). Solvent-free synthesis and $\mathrm{KOH}$ activation of mesoporous carbons using resorcinol/Pluronic F127/hexamethylenetetramine mixture and their application to EDLC. Microporous Mesoporous Mater. 272, 217-221. doi: 10.1016/j.micromeso.2018.06.028

Yu, X. Y., Yu, L., and Lou, X. W. (2016). Metal sulfide hollow nanostructures for electrochemical energy storage. Adv. Energy Mater. 6, 1-14. doi: 10.1002/aenm.201501333

Zhang, B., Kang, F., Tarascon, J.-M., and Kim, J.-K. (2015). Recent advances in electrospun carbon nanofibers and their application in electrochemical energy storage. Prog. Mater. Sci. 76, 319-380. doi: 10.1016/j.pmatsci.2015.08.002

Zhang, D., Zheng, L., Ma, Y., Lei, L., Li, Q., Li, Y., et al. (2014). Synthesis of nitrogen- and sulfur-codoped 3D cubic-ordered mesoporous carbon with superior performance in supercapacitors. ACS Appl. Mater. Interfaces 6, 2657-2665. doi: 10.1021/am405128j

Zhang, J., Jiang, J., Li, H., and Zhao, X. S. (2011). A high-performance asymmetric supercapacitor fabricated with graphene-based electrodes. Energy Environ. Sci. 4, 4009-4015. doi: 10.1039/C1EE01354H

Zhang, Q., Liu, Z., Zhao, B., Cheng, Y., Zhang, L., Wu, H.-H., et al. (2019). Design and understanding of dendritic mixed-metal hydroxide
nanosheets@N-doped carbon nanotube array electrode for highperformance asymmetric supercapacitors. Energy Storage Mater. 16, 632-645. doi: 10.1016/j.ensm.2018.06.026

Zhang, Q., Wang, X., Pan, Z., Sun, J., Zhao, J., Zhang, J., et al. (2017). Wrapping aligned carbon nanotube composite sheets around vanadium nitride nanowire arrays for asymmetric coaxial fiber-shaped supercapacitors with ultrahigh energy density. Nano Lett. 17, 2719-2726. doi: 10.1021/acs.nanolett.7b00854

Zhang, Z., Liu, M., Tian, X., Xu, P., Fu, C., Wang, S., et al. (2018). Scalable fabrication of ultrathin free-standing graphene nanomesh films for flexible ultrafast electrochemical capacitors with AC line-filtering performance. Nano Energy 50, 182-191. doi: 10.1016/j.nanoen.2018.05.030

Zhao, J., Lai, H., Lyu, Z., Jiang, Y., Xie, K., Wang, X., et al. (2015). Hydrophilic hierarchical nitrogen-doped carbon nanocages for ultrahigh supercapacitive performance. Adv. Mater. 27, 3541-3545. doi: 10.1002/adma.201500945

Zhao, Y., Ran, W., He, J., Song, Y., Zhang, C., Xiong, D. B., et al. (2015). Oxygen-rich hierarchical porous carbon derived from artemia cyst shells with superior electrochemical performance. ACS Appl. Mater. Interfaces 7, 1132-1139. doi: 10.1021/am506815f

Zhao, Z., and Xie, Y. (2018). Electrochemical supercapacitor performance of boron and nitrogen co-doped porous carbon nanowires. J. Power Sources 400, 264-276. doi: 10.1016/j.jpowsour.2018.08.032

Zheng, J. P., and Jow, T. R. (1995). a new charge storage mechanism for electrochemical capacitors. J. Electrochem. Soc. 142, L6-L8. doi: $10.1149 / 1.2043984$

Zhong, C., Deng, Y., Hu, W., Qiao, J., Zhang, L., and Zhang, J. (2015). A review of electrolyte materials and compositions for electrochemical supercapacitors. Chem. Soc. Rev. 44, 7484-7539. doi: 10.1039/C5CS00303B

Zhou, H., Zhu, S., Hibino, M., and Honma, I. (2003). Electrochemical capacitance of self-ordered mesoporous carbon. J. Power Sources 122, 219-223. doi: 10.1016/S0378-7753(03)00439-7

Zhou, Y., Xu, H., Lachman, N., Ghaffari, M., Wu, S., Liu, Y., et al. (2014). Advanced asymmetric supercapacitor based on conducting polymer and aligned carbon nanotubes with controlled nanomorphology. Nano Energy 9, 176-185. doi: 10.1016/j.nanoen.2014.07.007

Zhu, Y., Murali, S., Stoller, M. D., Ganesh, K. J., Cai, W., Ferreira, P. J., et al. (2011). Carbon-based supercapacitors produced by activation of graphene. Science 332, 1537-1541. doi: 10.1126/science. 1200770

Zhu, Y., Zong, Q., Zhang, Q., Yang, H., Wang, Q., and Wang, H. (2019). Three-dimensional core-shell NiCoP@NiCoP array on carbon cloth for high performance flexible asymmetric supercapacitor. Electrochim. Acta 299, 441-450. doi: 10.1016/j.electacta.2019.01.043

Conflict of Interest Statement: The authors declare that the research was conducted in the absence of any commercial or financial relationships that could be construed as a potential conflict of interest.

Copyright (c) 2019 Salinas-Torres, Ruiz-Rosas, Morallón and Cazorla-Amorós. This is an open-access article distributed under the terms of the Creative Commons Attribution License (CC BY). The use, distribution or reproduction in other forums is permitted, provided the original author(s) and the copyright owner(s) are credited and that the original publication in this journal is cited, in accordance with accepted academic practice. No use, distribution or reproduction is permitted which does not comply with these terms. 